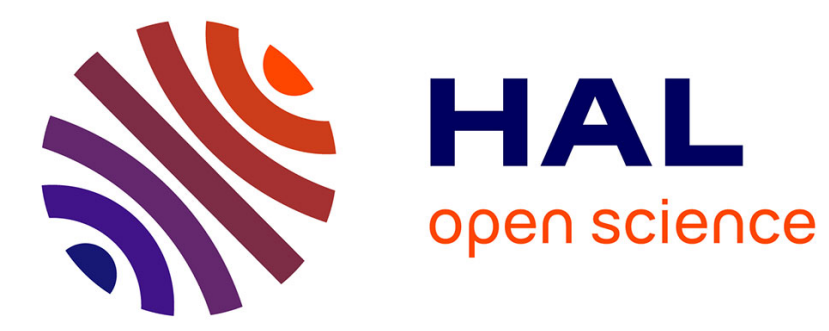

\title{
Materials for supercapacitors: When Li-ion battery power is not enough
}

Zhaoyang Lin, Eider Goikolea, Andrea Balducci, Katsuhiko Naoi, Pierre-Louis Taberna, Mathieu Salanne, Gleb N. Yushin, Patrice Simon

\section{- To cite this version:}

Zhaoyang Lin, Eider Goikolea, Andrea Balducci, Katsuhiko Naoi, Pierre-Louis Taberna, et al.. Materials for supercapacitors: When Li-ion battery power is not enough. Materials Today, 2018, 21 (4), pp.419-436. 10.1016/j.mattod.2018.01.035 . hal-02024384

\section{HAL Id: hal-02024384 https://hal.science/hal-02024384}

Submitted on 19 Feb 2019

HAL is a multi-disciplinary open access archive for the deposit and dissemination of scientific research documents, whether they are published or not. The documents may come from teaching and research institutions in France or abroad, or from public or private research centers.
L'archive ouverte pluridisciplinaire HAL, est destinée au dépôt et à la diffusion de documents scientifiques de niveau recherche, publiés ou non, émanant des établissements d'enseignement et de recherche français ou étrangers, des laboratoires publics ou privés. 


\section{Open Archive Toulouse Archive Ouverte (OATAO)}

OATAO is an open access repository that collects the work of Toulouse researchers and makes it freely available over the web where possible

This is an author's version published in: http://oatao.univ-toulouse.fr/21774

Official URL: https://doi.org/10.1016/j.mattod.2018.01.035

\section{To cite this version:}

Lin, Zhaoyang and Taberna, Pierre-Louis $\leftrightarrows$ and Salanne, Mathieu and Yushin, Gleb N. and Simon, Patrice $\leftrightarrows$ Materials for supercapacitors: When Li-ion battery power is not enough. (2018) Materials Today, 21 (4). 419-436. ISSN 1369-7021

Any correspondence concerning this service should be sent to the repository administrator: tech-oatao@listes-diff.inp-toulouse.fr 


\title{
Materials for supercapacitors: When Li-ion battery power is not enough
}

\author{
Z. Lin ${ }^{1,2}$, E. Goikolea ${ }^{3,4}$, A. Balducci ${ }^{5,6}$, K. Naoi ${ }^{7,8}$, P.L. Taberna ${ }^{1,2}$, M. Salanne ${ }^{2,9}$, \\ G. Yushin ${ }^{10}$, P. Simon ${ }^{1,2}$,*
}

\footnotetext{
${ }^{1}$ CIRIMAT, UMR CNRS 5085, Université Paul Sabatier, 118 route de Narbonne, 31062 Toulouse Cedex 9, France

${ }^{2}$ Réseau sur le Stockage Electrochimique de l'Energie (RS2E), FR CNRS 3459, 80039 Amiens Cedex, France

${ }^{3}$ CIC Energigune, Albert Einstein 48, Araba Technology Park, 01510, Miñano, Vitoria-Gasteiz, Spain

${ }^{4}$ Inorganic Chemistry Department, University of the Basque Country UPV/EHU, P.O. Box 644, 48080 Bilbao, Spain

${ }^{5}$ Institute for Technical Chemistry and Environmental Chemistry, Friedrich-Schiller-University Jena, Philosophenweg 7a, 07743 Jena, Germany

${ }^{6}$ Center for Energy and Environmental Chemistry Jena (CEEC Jena), Friedrich-Schiller-University Jena, Philosophenweg 7a, 07743 Jena, Germany

${ }^{7}$ Institute of Global Innovation Research (GIR), Tokyo University of Agriculture \& Technology, 2-24-16 Naka-cho, Koganei, Tokyo 184-8558, Japan

${ }^{8}$ Advanced Capacitor Research Center, Tokyo University of Agriculture \& Technology, 2-24-16 Naka-cho, Koganei, Tokyo 184-8558, Japan

${ }^{9}$ Sorbonne Université, CNRS, Physico-chimie des électrolytes et nano-systèmes interfaciaux, PHENIX, F-75005 Paris, France

${ }^{10}$ School of Materials Science and Engineering, Georgia Institute of Technology, Atlanta, GA 30332, USA
}

Supercapacitors, also known as electrochemical capacitors, have witnessed a fast evolution in the recent years, but challenges remain. This review covers the fundamentals and state-of-the-art developments of supercapacitors. Conventional and novel electrode materials, including high surface area porous carbons for electrical double layer capacitors (EDLCs) and transition metal oxides, carbides, nitrides and their various nanocomposites for pseudocapacitors - are described. Latest characterization techniques help to better understand the charge storage mechanisms in such supercapacitors and recognize their current limitations, while recently proposed synthesis approaches enable various breakthroughs in this field.

\section{Introduction}

Renewable energy technologies, energy efficient industrial equipment, individual, freight and public transport vehicles, portable electronic devices, and drones share a common requirement: they all need reliable electricity storage solutions. However, depending on the nature of the need (e.g., amount of energy, rate of charge or discharge, cycle stability, temperature of operations, etc.) and the location (e.g., in a centralized industrial power plant, in a direct contact with a consumer, etc.), the best available solutions may differ dramatically.

For example, the majority of the current energy storage facilities that offset the difference in the energy generation and electricity demands for the electrical grids are based on pumped

\footnotetext{
* Corresponding author at: CIRIMAT, UMR CNRS 5085, Université Paul Sabatier, 118 route de Narbonne, 31062 Toulouse Cedex 9, France.

E-mail address: Simon, P. (simon@chimie.ups-tlse.fr).
}

hydroelectric energy storage, in which the electricity is reversibly converted into potential energy. Such an energy storage solution is relatively low cost, but not always available for centralized locations and mostly not accessible for small-scale applications. In addition, it does not allow rapid electric energy conversion and release.

In case of portable applications, the use of solutions based on electrochemical energy storage systems is now well established. Among a large portfolio of the available technologies, the two currently most important ones are Li-ion batteries (LIBs) [1] and supercapacitors $[2,3]$ that offer different but often complementary performance characteristics. LIBs can deliver very large energy densities but commonly suffer from limited power densities and short cycle stability. They are, therefore, mostly used in applications where relatively small current densities are needed for longer (minutes to hours) time periods, such as portable electronics (cellular phones, laptops, tablets, headsets, fitness 
trackers, etc.), electric or hybrid electric vehicles (EVs and HEVs), and small-to-medium size stationary energy storage projects. At the same time, supercapacitors or electrochemical capacitors (ECs) can operate at high charge and discharge rates over an almost unlimited number of cycles. These are high-power devices that can be fully charged and discharged within a few seconds or a few tens of seconds. Typical applications of supercapacitors in transportation cover stop and start and regenerative braking systems in HEVs, which occurs on a timescale of a few seconds [2]. Tramways and buses have also already benefited from the development of supercapacitors and there are numerous examples of supercapacitor-powered electric buses (charging rapidly at bus stops) around the world, especially in China. Numerous cities in Europe, the US and worldwide are developing tramways and trains with on-board supercapacitor modules for braking energy recovery and short-distance electric drive (to pass crossings) in urban areas [4]. All those emerging applications for ECs in the automotive ecosystem suggest a bright future for this technology.

The main difference between LIBs and ECs lies in the charge storage mechanism: in short, the former involve redox reactions in the bulk of the active materials, while the latter operate through the accumulation of electrons at the surface of the electrode particles (as shown in Figure 1). While clearly more electrons can be stored in the bulk, kinetics limitations arise from the slow diffusion of the ions. In addition, LIBs operate in the electrochemical window where electrolyte is thermodynamically unstable. While the formation of passivation solid electrolyte interphase layer on the anode (SEI) and the cathode (typically called CEI) and the use of relatively large active particles (with small surface area in contact with electrolyte) may slow down electrolyte decomposition dramatically and permit 500-3000 or more deep cycles, such cycle stability is still very short compared to ECs which typically undergo $1,000,000$ or more cycles before degrading to $80 \%$ of the initial capacitance. Furthermore, replacement of electrolyte in ECs typically restores the initial performance.

In this review, we will focus on the materials employed for supercapacitor applications. Two main families are considered: electrical double-layer capacitors (EDLCs), which use nanopor-

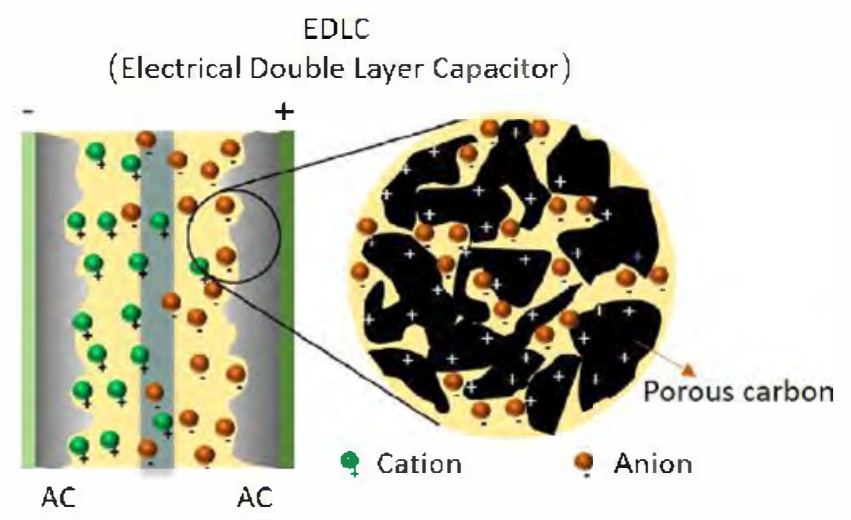

FIGURE 1

Schematic of an electrical double layer Capacitor (EDLC) and enlargement of porous carbon electrode interface, Co-ions are also present in both electrodes - they are omitted for clarity. ous carbon electrodes; and pseudocapacitors, which involve materials containing redox-active transition metals with multiple oxidation states. Those are generally oxide-based, but other sub-families of pseudocapacitive materials have recently been proposed. Even inside these families, the charge storage mechanisms are multiple and depend on both the electrode material (not only its chemical nature, but also its porosity, its texture, etc) and the electrolyte. In cases with constant capacitances, the energy $\mathrm{W}$ (Eq. (1)) and the maximum power densities $\mathrm{P}$ (Eq. (2)) are respectively given by

$W=\frac{1}{2} C V^{2} \quad(J)$

$P_{m}=\frac{V^{2}}{4 R}$

where $C$ is the capacitance (unit: F), $V$ is the operating voltage (unit: V) and $R$ is the equivalent series resistance (unit: $\Omega$ ) of the device.

This set of equations is only applicable to systems that show linear charge-discharge and rectangular cyclic voltammetry (CV) electrochemical signatures, i.e., when the charge Q (A.s) changes linearly with the potential. In the general way, the discharged energy is obtained by integrating the potential $\mathrm{V}$ (in $\mathrm{V})$ and the current $\mathrm{I}$ (in A) during the discharge time $\mathrm{t}(\mathrm{h})$ (Eq. (3)):

$W=\int V(t) I(t) d t$

and the power is the product of the potential multiplied by the current (Eq. (4))

$P=V(t) I(t) \quad(W)$

Current values for the commercial supercapacitor devices reach $8 \mathrm{Wh} / \mathrm{kg}\left(\approx 250 \mathrm{Wh} \mathrm{kg}^{-1}\right.$ for LIB) for the energy density and go beyond $10 \mathrm{~kW} / \mathrm{kg}\left(\approx 1 \mathrm{~kW} \mathrm{~kg}^{-1}\right.$ for LIB) for the power density. These performance characteristics typically change little (within 5-20\%) for more than 1,000,000 cycles of charge and discharge. After detailing the main factors and mechanisms that affect these performances for both EDCLs and pseudocapacitors, we will provide some perspectives on the materials and electrolytes that may be used in the future.

\section{Electrical double layer capacitors Carbon materials \\ Synthesis of porous carbons}

From the synthetic viewpoint, carbon offers the largest panel of choice for the porous electrodes. In fact, parameters such as material dimensionality (i.e., from zero dimensional to three dimensional materials), specific surface area, pore volume, and pore size distribution, particle size, and texture can be easily tuned by controlling the synthetic route parameters (albeit some of those can be difficult to characterize faithfully). Activated carbons (ACs) [5], carbide-derived carbons (CDCs) [6], templated carbons [5], and more recently graphene [7] have been the most explored as EDLC electrode materials. Carbon structures are still much more diverse, and carbon nanotubes (CNTs), carbon onions and mesoporous carbons have also been investigated $[8,9]$. 
ACs are the materials of choice for EDLC applications. They display a disordered structure obtained from the physical or chemical activation (partial oxidation) of a charcoal, hydrochar and other natural or synthetic organic precursors [10-13]. Physical activation is achieved at high temperature under a mixed inert/oxidizing atmosphere using typically steam or carbon dioxide as activation agents [11], whereas chemical activation is also performed at high temperature but mixing the precursor carbon with alkalis, carbonates, chlorides, acids, or similar reagents (e.g., $\mathrm{KOH}, \mathrm{K}_{2} \mathrm{CO}_{3}, \mathrm{H}_{3} \mathrm{PO}_{4}, \mathrm{H}_{2} \mathrm{SO}_{4}, \mathrm{ZnCl}_{2}$, among others) $[5,11]$. Most of the commercial EDLCs employ extra-pure steam activated ACs derived from coconut shells [5,11]. Chemical activation is mainly performed at the laboratory scale. It offers advantages in terms of pore size distribution control [5]. The maximum specific capacitance values in organic electrolyte are about $200 \mathrm{~F} \mathrm{~g}^{-1}$ and slightly over $60 \mathrm{~F} \mathrm{~cm}^{-3}$ [5]. Very recently even a capacitive response as high as $180 \mathrm{~F} \mathrm{~g}^{-1}$ and $80 \mathrm{~F} \mathrm{~cm}^{-3}$ in EMI-TFSI ionic liquid (IL) electrolyte has been attained in EDLCs using ACs [14].

CDCs were tested as EDLC materials at the beginning of the 2000s [15]. CDCs are microporous carbons (which means that their pore sizes are smaller than $2 \mathrm{~nm}$ ) with a very narrow pore size distribution. They are produced from high-temperature etching of metal carbides (TiC, SiC and VC among others) under chlorine gas atmosphere [16-18] or vacuum deposition $[19,20]$. They yield capacitance values up to $220 \mathrm{~F} \mathrm{~g}^{-1}$ and $126 \mathrm{~F} \mathrm{~cm}^{-3}$ in $\mathrm{KOH}$ and $150 \mathrm{~F} \mathrm{~g}^{-1}$ and $70 \mathrm{~F} \mathrm{~cm}^{-3}$ in organic electrolyte [16-20]. Commercial EDLCs based on CDC materials offer superior energy densities. High power can be achieved as well, for instance, by introducing mesopore channels for fast ion transport [21] or using nano-felts like CDC electrodes [22]. However, the cost of CDC materials is higher than that of ACs, which limits their applications.

Templated carbons using zeolite as a sacrificial porous structure directing agent have been developed [23-25]. These carbons exhibit extremely narrow pore size distribution, with a high specific surface area. Such optimum properties lead to both very

high gravimetric (about $150 \mathrm{~F} \mathrm{~g}^{-1}$ ) and volumetric $\left(80 \mathrm{~F} \mathrm{~cm}^{-3}\right)$ capacitance in non-aqueous electrolyte. However, the preparation of zeolite-templated carbons has been limited to the laboratory-scale due to the challenges in scaling-up the synthesis process while maintaining material uniformity and the high costs associated with the need of HF for dissolving the hard template.

Graphene and graphene-like carbons became recently popular, but conventional commercial graphene powders suffer from (i) restacking of graphene layers, which drastically reduces the surface area and capacitance values, and (ii) low electrode density, which results in poor volumetric capacitance values. Chemical activation with $\mathrm{KOH}$ can be used to produce activated graphene with a large specific surface area and a broad pore size distribution (ranging between 0.6 and $5 \mathrm{~nm}$ ). Such activated graphene delivers a capacitance of $160 \mathrm{~F} \mathrm{~g}^{-1}$ and $60 \mathrm{~F} \mathrm{~cm}^{-3}$ in acetonitrile-based non aqueous electrolyte [26]. This is one of the few examples [26-29] showing electrochemical performance comparable to ACs since in most cases, the low density of graphene limits the energy density of the device both in gravimetric and volumetric terms [30]. Beyond graphene, there are many other two-dimensional carbons, such as reduced graphene oxide, or exfoliated graphite flakes. To avoid confusion, it's recommended to use the appropriate nomenclature instead of the generic term "graphene" for all two-dimensional carbons [31].

Surface functional groups on various nanostructured carbons (carbon onions, activated carbon, graphene, CNTs, etc.) may enhance capacitance in both organic and aqueous electrolytes substantially, but at the expense of undesired gassing during operation, faster self-discharge $[32,33]$ and reduced stability when assembled into fully functional, dense, multi-layered hermetic devices, particularly at elevated temperatures.

In summary, many different forms of carbon materials have been prepared and tested for supercapacitor applications during the past 20 years. New synthesis methods have been proposed to prepare high-capacitance materials at the laboratory scale. The various strategies consisted in controlling the porosity, the average pore size and pore size distributions, as well as the texture and defect content $[5,10,23,34]$ of the materials. This knowledge has then been transferred to the case of ACs, which remains the materials of choice for commercial EDLC devices for cost reasons. In the following, we will discuss more precisely the current knowledge on the role played by the key parameters in the enhancement of the performances.

Specific surface area and pore size distributions in porous carbons According to the first model proposed by Helmholtz $[2,35,36]$, the capacitance of the double-layer is given by

$C=\frac{\varepsilon_{r} \varepsilon_{0} A}{d}$ or $\frac{C}{A}=\frac{\varepsilon_{r} \varepsilon_{0}}{d}$

where $d$ is the distance between the layer of charge on the electrode and the layer of adsorbed ions, $e_{\mathrm{r}}$ is the electrolyte dielectric constant, $e_{0}$ is the permittivity of vacuum and $A$ is the electrode surface area. Eq. (5) suggests that capacitance increases linearly with the latter, so that developing high specific surface area (SSA) carbons has long been the main strategy for optimizing EDLCs.

Yet, the SSA value depends substantially on both the measurement and analysis methods, in particular in the presence of micropores and polar groups in the material. The International Union of Pure and Applied Chemistry has recently confirmed that the widely used Brunauer-Emmett-Teller analysis (BET) is not recommended for microporous carbons analysis because it underestimates the surface of ultramicroporous $(<0.7 \mathrm{~nm})$ carbons and overrates the surface of large micropores $(>0.7 \mathrm{~nm})$ $[3,37]$. Other methods available for evaluating carbon textural properties, such as the Dubinin-Radushkevich equation or immersion calorimetry, also lack the precision needed for providing conclusion on the dependence of capacitance on pore size [38]. To avoid the interaction of functional groups or heteroatoms in carbon with molecular electric quadrupole moment of $\mathrm{N}_{2}$ or molecular electric dipole moment of $\mathrm{CO}_{2}$, the determination of the SSA of microporous carbons should preferably be done by measuring the adsorption of $\mathrm{Ar}$ gas at $87 \mathrm{~K}$. Then the analysis of the isotherms using Density Functional Theory (DFT), Non Local DFT (NLDFT) or Quenched Solid Density Functional Theory (QSDFT) mathematical models provide the pore size distribution and the mean pore size diameter, in addition 
to the SSA [39]. However, commercial software packages utilizing these methods currently rely on the simple models for the shape of the pores (e.g., infinitely wide slit pores or infinitely long cylindrical pores), which are not accurate. Furthermore, the key quantity that should be considered to calculate the specific capacity (in $\mathrm{F} \mathrm{m}^{-2}$ ) of the porous carbons is the surface area accessible to the ions of the electrolyte (e.g., defined by considering the pore sizes larger than the neat ion size [40]). In addition, whatever the approach used, estimations based on gas adsorption always rely on mathematical models. Finally, other parameters such as surface chemistry (presence of heteroatoms, surface groups or defects) or texture also affect the capacitance $[34,41]$ and such impacts depend on electrolyte used due to the complex interactions between electrolyte solvent molecules, electrolyte ions, functional groups and carbon surface. Due to the difficulty of linking the performance of the materials to a few wellcontrolled parameters, advanced experimental techniques such as X-ray [42,43] or neutron scattering [44] combined with modeling have been developed over the past years to get a better understanding of the ion confinement effect in carbon nanopores and the associated capacitance increase. In general, these studies aim at characterizing directly the adsorption of the ions, and hence they focus on the interface rather than on the carbon material only.

\section{Electrolytes}

Ideal electrolyte for electrical double layer capacitors

The charge storage mechanism in electrical double layer capacitors (EDLCs) relies on the adsorption of the ions of an electrolyte onto the pore surface of a porous electrode. For this reason, the electrolyte has to be considered as an active material just like the electrode materials [2,45-48]. Typically, an EDLC electrolyte contains a salt (in a concentration of $1 \mathrm{~mol} \mathrm{~L}^{-1}$ or higher) and a solvent.

As indicated above (see Eqs. (1) and (2)), both the energy and the power of EDLCs depend at first order on the square of the operating voltage, and thus on the electrochemical stability of the electrolyte, because the formation of SEI or CEI on EDLC electrodes would dramatically reduce their performance and cycle life. The stability is therefore one of the most important properties to optimize. Additionally, the fast and efficient storage process required for EDLC highlights the needs for low viscosity (commonly correlated with high ion mobility) and high conductivity (proportional to the multiple of the ion mobility and ion concentration) electrolytes in a broad range of operating temperatures. In order to guarantee a long cycle life, which is one of the strengths of EDLCs, the integrity of the electrolyte solvents and salts need to be preserved. Consequently, a high (electro)chemical stability is also a very important requirement for the electrolyte components. In order to maximize addressable markets, EDLCs should ideally be able to operate safely in temperatures ranging between $-60^{\circ} \mathrm{C}$ and $100^{\circ} \mathrm{C}$. In order to establish a safe operation in this broad operative range, low melting, high boiling points and high flash point of the electrolytes are required. Finally, all these properties should be displayed by a cheap electrolyte based on low-cost and preferably low-toxicity salts and solvents, which is needed for the successful commercialization of any electrochemical storage device for large markets.

\section{State-of-the-art: organic electrolytes}

Commercial EDLCs contain either aqueous or organic-based electrolytes $[2,45,46]$. Aqueous systems are currently limited to low cell voltage, so the state-of-the-art organic electrolytes consist of solutions containing $1 \mathrm{M}$ of the salt tetraethylammonium tetrafluroroborate $\left(\mathrm{Et}_{4} \mathrm{NBF}_{4}\right)$ in acetonitrile $(\mathrm{ACN})$ or propylene carbonate (PC) $[2,45,46]$. These electrolytes display good transport properties, and their use makes possible the realization of EDLCs with operative voltage in the order of 2.7-2.8 V, able to work in a rather broad temperature range. Typically, ACNbased EDLC display higher power and higher performance at low temperatures compared to PC-based EDLCs. However, many studies showed that these electrolytes cannot operate at voltages higher than 2.8-3.0 V without a dramatic reduction of their cycle life [46-48]. As a consequence, the development of innovative electrolytes allowing higher voltages is considered as a priority for this technology.

\section{Alternative electrolytes for EDLCS}

Figure 2 shows a schematic summary of the various electrolyte components recently reported, and Table 1 lists some of the chemical-physical properties as well as the operative voltage of EDLCs of these innovative electrolytes. In the following, these results will be considered and critically analyzed.

Alternative solvents and conducting salts. In the last years, several nitrile-based electrolytes such as glutaronitrile (GTN) [49-51], adiponitrile (ADN) [51-56], butyronitrile (BTN) [54,55], and 2-methylglutaronitrile (2-MGN) [51], have been investigated as replacements of ACN. These solvents have been used in combination with $\mathrm{Et}_{4} \mathrm{NBF}_{4}$ as well as other conducting salts [49-57]. They typically display lower ionic conductivities compared to ACN-based electrolyte. Nevertheless, their use makes possible, in many cases, the realization of EDLC with higher voltage compared to the state-of-the-art [48]. For example, ADN-based electrolytes allow an operating voltage as high as $3.5 \mathrm{~V}$, and good overall performance at room temperature $[51,52]$. Nevertheless, due to the relatively high viscosity of these electrolytes, their performance in power density is significantly lower [52].

Carbonates, e.g., ethylene carbonate (EC) and dimethyl carbonate (DMC) are largely used as solvent electrolytes in lithium-ion batteries (LIBs) [58]. In the past years, mixtures of these carbonates in combination with lithium hexafluorophosphate $\left(\mathrm{LiPF}_{6}\right)$ have been proposed as electrolytes for EDLCs. These mixtures display high conductivity and rather large electrochemical stability, and it has been shown that their use enables operating voltage higher than $3 \mathrm{~V}$ [59-61]. However, the performance and the safety of these devices are limited by their electrochemical stability and the high flammability of the solvents, as well as by the poor chemical and thermal stability of $\mathrm{LiPF}_{6}$ [58]. Also, butylene carbonate (BC) has been considered as alternative for $\mathrm{PC}$ to increase the operating voltage beyond $3 \mathrm{~V}$ [62]. Nevertheless, the overall performance of BC-based EDLCs does not appear superior to the one of conventional systems.

Besides nitriles and carbonates, other categories of solvents have also been investigated in the past. Sulfone-based electrolytes (e.g., ethyl isopropyl sulfone) have been proposed, to design $3.2 \mathrm{~V}$ EDLC cells with good electrochemical performance [63]. Very 


\begin{tabular}{|c|c|c|}
\hline \multicolumn{3}{|c|}{ Conventional electrolytes for EDLCs } \\
\hline $\begin{array}{l}\text { Solvents } \\
\text { - Acetonitrile (ACN) } \\
\text { - Propylene Carbonate (PCi }\end{array}$ & $\begin{array}{l}\text { Salts } \\
\text { Cation } \\
\text { - Tetra-ethylammonium }\left(\mathrm{Et}_{4} \mathrm{~N}^{\prime}\right) \\
\text { Anion } \\
\text { - Tetra fluoroborate }\left(\mathrm{BF}^{4}\right)\end{array}$ & \\
\hline
\end{tabular}

\section{FIGURE 2}

Overview of the solvents and salts utilized in conventional and alternative electrolytes for EDLCs.

recently, Balducci and co-worker proposed 3-cyanopropionic acid methyl ester (CPAME) as new solvent for EDLCs [64,65]. It has been shown that CPAME-based EDLCs could display operating voltages as high as $3.5 \mathrm{~V}$ and high capacitance retention during float test carried out at $3.2 \mathrm{~V}$ [64]. It is interesting to notice that CPAME has been identified using a computational screening method, a novel strategy which will be further detailed in the perspective section of this review. The use of ether and ester cosolvents, such as methyl acetate (MA), methyl formate (MF), and 1,3-dioxolane (DIOX), has been explored to enhance lowtemperature performance of EDLCs down to -60 and $-70{ }^{\circ} \mathrm{C}$ [66-69], although at the expense of reduced high-temperature stability and little-to-no positive impact on the maximum operating voltage.

Since the ions of the conducting salt are directly involved on the double layer formation and structure, the composition of the conducting salt also is of crucial importance. However, surprisingly, only relatively few alternative salts have been considered in the past $[45,47,48]$. Among them, quaternary ammonium and phosphonium-based cations have been the first to be proposed, most of the time in combination with tetrafluoroborate $\left(\mathrm{BF}_{4}^{-}\right)[50,66,70]$. More recently, salts based on the pyrrolidinium cation have been also proposed $[50,70,71]$. Regarding the anion, aside from $\mathrm{BF}_{4}^{-}$, the bis(trifluoromethansulfonyl)imide $\left(\mathrm{TFSI}^{-}\right.$), anion has been the most investigated $[47,70]$. Several cationanion combinations were considered for the realization of innovative salts, and have been used in combination with PC and ACN $[70,72]$. These studies showed that a proper ion selection is crucial for the realization of advanced electrolytes and makes possible, especially when $\mathrm{PC}$ is used as a solvent, the realization of EDLCs with operating voltages of 3.3 to $3.5 \mathrm{~V}$, leading to high energy and power density $[70,72]$. Nevertheless, more systematic investigations about the influence of the anion-cation and ion-solvent interactions on the chemical-physical and electrochemical properties in these novel electrolytes are still needed.

Solvent-free electrolytes: ionic liquids and their derivatives. Since the solvent does not directly contribute to the storage process, it was originally hypothesized that its content should be as low as possible in order to maximize the energy and the power densities of the device [48,73-75]. Ionic liquids (ILs), which are solvent-free electrolytes, have therefore attracted much interest as alternative electrolytes for EDLC applications. The best candidates display high electrochemical and chemical stability [76-78], and melting points below $0^{\circ} \mathrm{C}[46,77]$. Many publications have been dedicated to the use of aprotic ILs (AILs) in EDLCs $[46,47,76,77]$. Different type of cations, e.g., pyrrolidinium [79-86], imidazolium [87-92], azepanium [93-95], sulfonium and cyclic sulfonium [96-99] and anions, e.g., TFSI ${ }^{-}$ [45-48], bis(fluorosulfonyl)imide ( $\mathrm{FSI}^{-}$) $[45,84,91,100]$, dicyanamide $\left(\mathrm{DCA}^{-}\right)$[101-103], tricyanomethanide $\left(\mathrm{C}(\mathrm{CN})_{3}^{-}\right)$[104], $\mathrm{BF}_{4}^{-}[45,71,76], \mathrm{PF}_{6}^{-}[45,71,105]$ have been investigated. These studies indicated that, when a proper anion-cation combination is selected, ILs allow to reach high voltage ( $>3 \mathrm{~V}$ ) devices, which are able to work in a wide range of temperatures (especially when eutectic mixture of ILs are used) $[9,76]$. Their power performance is, however, limited by the relative high viscosity of ILs, especially at room temperature and below.

Protic ionic liquids (PILs) have also been investigated for use in EDLCs [77,106-109]. PIL-based EDLCs show stable performance, within a broad range of temperatures [109]. However, the presence of labile proton(s) in the cation is limiting the electrochemical stability, and, consequently, the operative voltage of PIL-based EDLCs is significantly lower than that of AIL-based devices (2.5 V for PIL vs. 3-3.5 V for AILs) [109]. For this reason, their use in EDLC does not appear to be particularly interesting. 
Comparison of viscosities and conductivities of conventional and selected alternative electrolytes for EDLCs. The table indicates also the operative voltage of EDLCs containing these electrolytes.

\begin{tabular}{|c|c|c|c|}
\hline Electrolyte & Viscosity (mPa s) & Conductivity $\left(\mathrm{mS} \mathrm{cm}^{-1}\right)$ & Operating voltage (V) \\
\hline \multicolumn{4}{|l|}{ Conventional } \\
\hline $1 \mathrm{M} \mathrm{Et}_{4} \mathrm{NBF}_{4}$ in $\mathrm{ACN}$ [46] & 0.6 & 56 & 2.7 \\
\hline $1 \mathrm{M} \mathrm{Et}_{4} \mathrm{NBF}_{4}$ in $\mathrm{PC}[46]$ & 2.5 & 15 & 2.7 \\
\hline \multicolumn{4}{|l|}{ Alternative } \\
\hline \multicolumn{4}{|l|}{ Solvents } \\
\hline \multicolumn{4}{|l|}{ Nitrile } \\
\hline $1 \mathrm{M} \mathrm{Et}_{4} \mathrm{NBF}_{4}$ in GTN [51] & 8 & 6.1 & 2.7 \\
\hline $0.7 \mathrm{M} \mathrm{Et}_{4} \mathrm{NBF}_{4}$ in $\mathrm{ADN}$ [51] & 9.5 & 3.5 & 3.5 \\
\hline $0.2 \mathrm{M} \mathrm{PYR}_{14}$ TFSI in BTN [54] & 3 & 17 & 3.2 \\
\hline $0.5 \mathrm{M} \mathrm{Et}_{4} \mathrm{NBF}_{4}$ in 2-MGN [51] & 9 & 2.3 & 3 \\
\hline \multicolumn{4}{|l|}{ Carbonate } \\
\hline $0.8 \mathrm{Et}_{4} \mathrm{NBF}_{4}$ in 2,3 BC [49] & 4 & 7.5 & 3.2 \\
\hline $1 \mathrm{M} \mathrm{Li-PF_{6 }}$ in EC-DMC (3:7) [61] & 2.7 & 11.8 & 3 \\
\hline \multicolumn{4}{|l|}{ Sulfonate } \\
\hline $0.6 \mathrm{M} \mathrm{Et}_{4} \mathrm{NBF}_{4}$ in EiPS [50] & 5.6 & n.a & 3.2 \\
\hline \multicolumn{4}{|l|}{ Cyano ester } \\
\hline $0.6 \mathrm{M} \mathrm{Et}_{4} \mathrm{NBF}_{4}$ in CPAME [64] & 5.5 & 4.3 & 3.2 \\
\hline \multicolumn{4}{|l|}{ Salts } \\
\hline $1 \mathrm{M} \mathrm{PYR}_{14}$ TFSI in ACN [72] & 1.6 & 40 & 3.1 \\
\hline $1 \mathrm{M} \mathrm{PYR}_{14}$ TFSI in PC [70] & 5 & 10 & 3.5 \\
\hline $1 \mathrm{M} \mathrm{PYR}_{14} \mathrm{BF}_{4}$ in $\mathrm{PC}[70]$ & 4 & 10 & 3.2 \\
\hline $1 \mathrm{M} \mathrm{PYR}_{14} \mathrm{BF}_{4}$ in ACN [72] & 0.8 & 50 & 3.1 \\
\hline \multicolumn{4}{|l|}{ Solvent-free } \\
\hline $\mathrm{PYR}_{14}$ TFSI [76] & 60 & 2.6 & 3.5 \\
\hline Azp $_{14}$ TFSI $\left(60^{\circ} \mathrm{C}\right)[94]$ & 38 & 3.6 & 3.5 \\
\hline $\mathrm{PYR}_{14} \mathrm{DCA}[103]$ & 37 & 10 & 2.5 \\
\hline $\mathrm{PYR}_{14} \mathrm{FSI}-\mathrm{PIP}_{13} \mathrm{FSI}[9]$ & n.a. & 4.9 & 3.5 \\
\hline EMIM-TFSI [76] & 28 & 8.4 & 3.5 \\
\hline $\mathrm{Et}_{3}$ NHTFSI [109] & n.a. & 4 & 2.4 \\
\hline 0.5 M Biredox in BMIMTFSI [110] & n.a. & 3.2 & 2.8 \\
\hline
\end{tabular}

More recently, a new class of ILs attracted a considerable attention: the redox active ILs [110-112]. These ILs contain redox-active moieties, e.g., anthraquinone and TEMPO, which are actively contributing to the energy storage through fast and highly reversible faradic reactions. The use of these ILs appears very interesting since the simultaneous utilization of nonfaradic and faradic storage processes drastically improves the EDLC's energy. Nevertheless, many aspects related to the use of these electrolytes, e.g., self-discharge and cycle life, need to be further clarified to really assess the advantages related to the use of this class of ILs.

In parallel with the work in regular IL electrolytes, IL-based solid electrolytes have been investigated. Polymeric ionic liquids [113], polymeric electrolytes containing ILs [114] and ILs confined in ionogel [115] have been proposed and tested. The results of these investigations appear promising at room and elevated temperatures. Nevertheless, the impacts of these solid electrolytes on the power density at low temperatures and the long-term electrochemical performance need to be better understood. The use of alternative conducting salts appears currently the most effective strategy to design EDLCs with high energy, high cycle life and acceptable power (see Figure 3) $[47,48]$. Nevertheless, further studies are required to understand the behavior at high/low temperatures of EDLCs containing these alternative salts. The introduction of novel solvents is certainly a promising strategy, and encouraging results have been obtained in the last years. However, the power of EDCLs containing these solvents should be improved [48]. In that aim, more systematic investigations of the solvent-salt interactions appear urgently needed.

In conclusion, alternative electrolytes based on ILs and their derivatives often allow to go beyond the state-of-the-art for the operative voltage, but this is generally made at the price of poorer transport properties, reduced operating voltage, increased costs, or other limitations. The last important parameter for assessing the performance is the capacitance, which commonly does not depend on the electrolyte in a pure EDLC (as soon as good wetting is achieved in all the pores) since the double layer formation is an interfacial property. The current knowledge on how this quantity can be maximized is discussed next.

Charge storage mechanisms at the electrolyte/carbon interface Major advances have been made in the understanding of the ion transfer and adsorption in carbon pores during the past fifteen years. Following initial work from several groups in the world $[18,116-118]$, the key contribution of pores with a size smaller than $1 \mathrm{~nm}$ to the charge storage mechanism was evidenced from electrochemical experiments using CDC carbons with controlled pore sizes as model materials $[2,15,119]$. These first studies were performed in organic electrolytes, in which the size of the solvation shell of ions such as $\mathrm{NEt}_{4}$ or $\mathrm{BF}_{4}$ is above carbon pore size. 

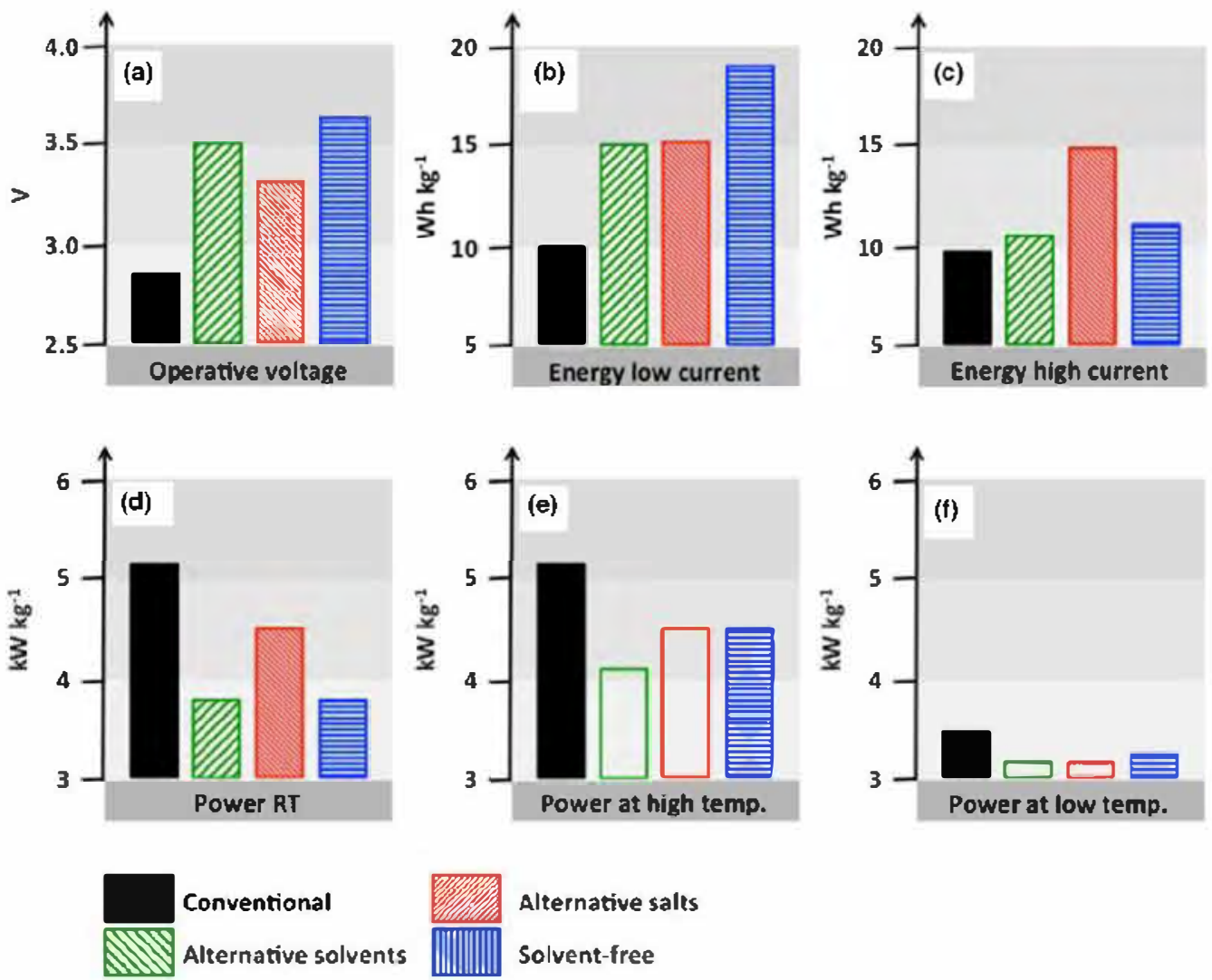

\section{FIGURE 3}

Comparison of (a) operative voltage; (b) energy density at low-current density $\left(0.1 \mathrm{~A} \mathrm{~g}^{-1}\right)$; (c) energy density at high-current density (>1 $\left.\mathrm{A} \mathrm{g}^{-1}\right)$; (d) power density at room temperature; (e) power density at high temperature and (f) power density at low temperature of conventional and alternative electrolytes for EDLCs. The green and the red columns in (e) and (f) represent a projection because no date is available in literature (for this reason the columns are empty). Adapted with permission from Ref. [48].

The partial ion desolvation was proposed to explain the capacitance increase in these nanopores [15,119]. Further electrochemical experiments in solvent-free ionic liquid electrolytes have shown a maximum capacitance when the ion size was close to the carbon pore size [120].

At that point, conventional electrochemical experiments failed short bringing additional information about the ion organization and environment in confined pores because of the sensitivity needed to explore the microscopic scale. An important step was achieved in the understanding of the charge storage mechanism thanks to the key contribution of theoreticians, who joined the field and developed models to depict the "double layer" structure in nanopores [121-124]. The first simulations involved ideal carbon structures such as carbon nanotubes or 2-dimensional slit-shaped pores, in which the capacitance increase in nanopores was qualitatively reproduced $[125,126]$. A key result was the prediction of a "superionic state": ions carrying similar charges can be densely packed together inside nanopores thanks to the creation of image charges onto the carbon surface that screens the Coulombic repulsion between them (Figure 4a) [127].

Then, the use of realistic 3D carbon structures to perform simulations led to important advances (Figures $4 b, 5 a$ ). CDC carbon structures were used in a series of molecular dynamics simulations to study ion adsorption from neat ionic liquid and ionic plus solvent mixtures. In neat $\mathrm{BMI}_{-} \mathrm{PF}_{6}$ ionic liquid electrolyte, the capacitance increase was ascribed to the breaking of the layered arrangement which is observed on planar surface, which led to the absence of over-screening effect. As a consequence, a closer approach of the adsorbed ions to the carbon surface was obtained [128]. When dissolved in acetonitrile, $\mathrm{BMI}^{+}$and $\mathrm{PF}^{-}$ ions confined into nanopores were found to be partially desolvated compared to bulk electrolyte (see Figure 5a) [128,130]. However, only acetonitrile molecules were present in the highly confined pores at null potential. Interestingly, under external polarization, ions tend to replace them inside these confined pores leading to an efficient charge storage mechanism. This effect was quantified by showing the relationship between the surface charge and the degree of confinement of the ions.

Those modeling results have drawn the interest of experimentalists who started to design advanced techniques or combined techniques to track ion fluxes in porous carbon electrodes.

Electrochemical quartz microbalance (EQCM) [132,133], nuclear magnetic resonance (NMR) [134,135], small-angle X-ray spectroscopy (SAXS) [136] and small angle neutron scattering (SANS) [137] are examples of in-situ or operando advanced 
(a)

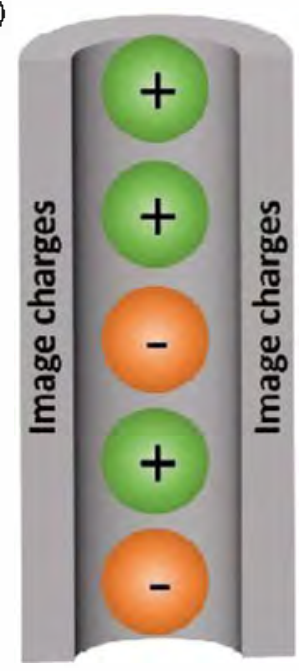

(b)
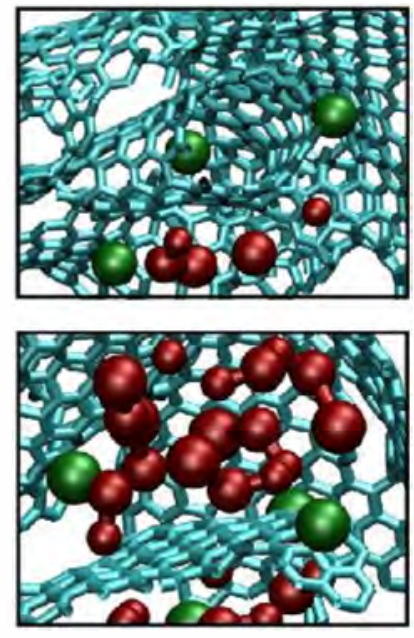

(c)

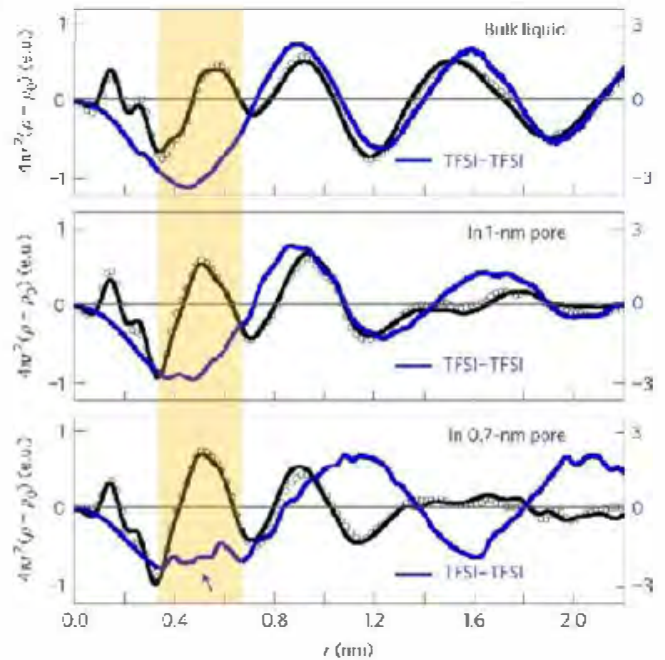

\section{FIGURE 4}

Formation of a superionic state in electrified nanopores: from theory to experiments. (a) Mean field-theory have first predicted that the presence of image charges at the surface of the nanoporous carbon exponentially screen out the electrostatic interactions of ions, leading to the packing of ions of the same sign; (b) molecular dynamics simulations of a supercapacitor formed with a CDC electrode and a BMI-PF 6 ionic liquid have displayed the formation of such structures (green: $\mathrm{PF}_{6}^{-}$anions, red: $\mathrm{BMI}^{+}$cations, turquoise sticks: carbon-carbon bonds). Reproduced with permission from Ref. [128]; (c) Scattering experiments have finally confirmed the existence of anion-anion correlations in the nearest-neighbor region when they are adsorbed in 0.7-nm pores. Reproduced with permission from Ref. [129].

(a)

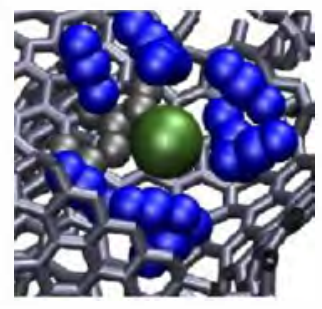

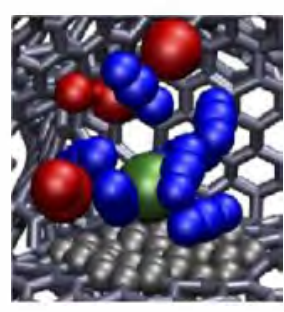

(b)

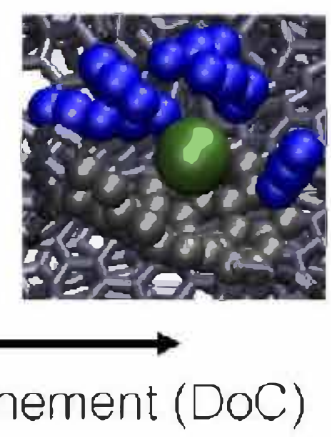

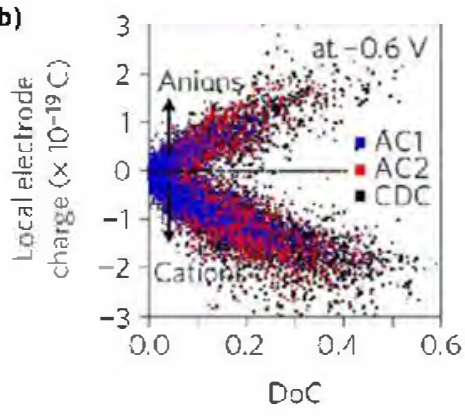

\section{Increasing degree of confinement (DoC)}

\section{FIGURE 5}

Impact of the degree of confinement of the ions on the local surface charge. (a) Molecular dynamics simulations have evidenced the existence of various adsorption sites for the ions inside nanoporous carbons, for which a degree of confinement (DoC) can be confined. Here PF6- anions (green spheres) adsorbed on sites with increasing DoC are shown from left to right (blue: ACN molecules, red: 1-butyl-3- methylimidazolium cations, gray spheres and sticks: carbon electrode). Reproduced with permission from Ref. [130]; (b) In situ small-angle X-ray scattering experiments have confirmed the correlation between the magnitude on the local electrode charge with the $\mathrm{DoC}$ of the adsorbed ions for a $\mathrm{CsCl}$ aqueous electrolyte adsorbed in various nanoporous carbons (AC1, $\mathrm{AC2}$ and $\mathrm{CDC}$ ). Reproduced with permission from Ref. [131].

techniques which have been recently successfully used to study the ion adsorption mechanism and ion environment in carbon nanopores.

EQCM technique has been used for tracking ion dynamics into porous carbon electrodes. In gravimetric mode, EQCM measures the carbon electrode mass changes during electrochemical polarization [133,138]. Pioneer studies using aqueous-based electrolytes highlighted the potential of gravimetric EQCM for the analysis of ion concentration and compositional changes as well as the solvation state within the AC pore volume [138,139]. More recently, a similar approach has also been proposed in non-aqueous electrolytes [133]. The partial desolvation of ions in carbon nanopores ( $<1 \mathrm{~nm}$ size) suggested by simulation results was experimentally evidenced from gravimetric measurements in acetonitrile-based electrolytes, with a loss of $50 \%$ of the cation solvation shell when confined in narrow pores. Surprisingly, two different charge storage mechanisms were reported, depending on the electrode polarity: counter-ion (cation) adsorption at negatively charged electrodes and ion exchange during positive polarization [133].

Besides the gravimetric EQCM technique, another approach has been proposed by Levi et al. $[139,140]$ who developed the Electrochemical QCM with dissipation monitoring technique (EQCM-D) for batteries and supercapacitor studies. Fitting the EQCM-D data with suitable hydrodynamic models allows tracking the change of the geometric parameters of porous electrodes 
in contact with an electrolyte. Such technique, that uses complex mathematical analysis, offers interesting opportunities to study the structural change of the electrodes [139].

NMR is an element selective technique that has also been used for studying ion electro-sorption in microporous carbons. A pre-

liminary ex-situ NMR study shed some light on the cation/anion population in different porous carbon sites upon charging [141].

In-situ NMR experiments first confirmed the ion adsorption in nanopores in the absence of polarization (at $0 \mathrm{~V}$ ) thanks to the shift of the NMR signal at low frequency $[142,143]$. The comparison of different charge mechanisms was made by introducing the charging mechanism parameter " $X$ ", calculated from in-situ NMR experiments or from molecular dynamic (MD) simulations [143]. Results have shown that ion swapping plays an important role in the charge storage process in supercapacitor electrodes. Ion swapping also was established as the main feature of ion dynamics for aqueous neutral electrolytes using in-situ SAXS measurements [143]. SAXS is a short-range order structural characterization technique able to provide information on ion concentration and location.

Due to high penetrative power of neutrons and the sensitivity of neutron scattering to isotope substitution, SANS allows one to directly observe changes in the ion concentration as a function of the applied potential and the pore size, independently of other parameters (such as carbon surface chemistry, carbon microstructure, etc.) [44]. In-situ SANS experiments demonstrated that depending on the carbon pore walls - electrolyte interactions and the resulting interfacial energy, both reduced and enhanced ion sorption is possible in sub-nm pores [44]. Furthermore, SANS allowed visualization of the organic electrolyte electrowetting in the smallest pores at higher applied potentials [137].

Additionally, new methodologies based on the combinatory approach of various in-situ techniques have opened new horizons in the understanding and prediction of ion electrosorption

in microporous carbons. In-situ EQCM and NMR [144] techniques confirmed the difference in the charge storage mechanism in acetonitrile-based electrolyte, with cation adsorption under negative polarization and ion swapping during positive polarization.

The most recent experimental studies confirmed the main concepts introduced by theoretical and simulation studies. For example, the relationship between the degree of confinement and the local surface charge [128] was confirmed by Prehal et al. [131]. They studied the confinement and desolvation in nanometer-sized carbon pores of $1 \mathrm{M} \mathrm{CsCl}$ in water electrolyte, by combining in-situ SAXS together with Monte Carlo simulations. By modeling back the experimental SAXS data, they found that the extent of desolvation was increased when decreasing the average pore size of microporous carbons (see Figure $5 b$ ). In another example, the existence of the superionic state introduced by Kondrat and Kornyshev [127] (Figure 4a and b) was experimentally proven by performing scattering experiments to resolve the structure of the EMI-TFSI ionic liquid confined inside nanoporous carbons [129]. Indeed, the latter study showed that Coulombic ordering (cations alternatively with anions) was partly reduced when the pores were small enough to accommodate only one single layer of ions (Figure 4c). Instead, equally charged ion pairs are formed due to the induction of an electric potential of opposite sign in the carbon pore walls. This nonCoulombic ordering was further enhanced in the presence of an applied external electric potential. This approach provides guidelines for designing porous carbons for supercapacitors, i.e., with high electrical conductivity and pore structure inducing larger image charges at the surface. The conclusions of this study should be applicable to other conducting materials forming slitpores, such as between 2D layers of transition metal dichalcogenides, MXene and metal oxides (as will be discussed in the next sections).

Going beyond simple understanding, these fundamental studies have allowed to adapt the synthesis routes of the manufacturers. They now aim at AC materials with controlled average pore size and pore size distributions in the microporous range (see e.g., the YP series microporous carbons from Kuraray, a leading company in porous carbons for EDLCs [145]) that offer enhanced volumetric capacitance and try to achieve carbon surface cleaned from surface groups that offer improved cycle and voltage stability and reduced self-discharge [146].

\section{Pseudocapacitive materials and hybrid devices}

\section{Metal oxide pseudocapacitive materials}

Improving the capacitance of materials can be achieved by moving from porous carbon, which store the charge in the double layer by ion adsorption at the carbon surface, to so-called pseudocapacitive materials. In the 1970's, Conway and others recognized that when reversible (fast) redox reactions occur at or near the surface of an appropriate electrode material, the electrochemical features are those of an EDLC, but with significantly greater charge storage because of the presence of redox reactions [36]. The pseudocapacitive mechanism was firstly described in $\mathrm{RuO}_{2}$ materials (Figure 6a), where the capacitive-like behavior rectangular shape of the voltammogram - was attributed to the existence of a wide energy distribution for the adsorbed protons in accessible sites located on the surface of $\mathrm{RuO}_{2}$ particles (Frumkin-like behavior with non-potential dependent capacitance) $[36,147]$. A pseudocapacitive process shows several key features such as (i) a continuous change of the charge with the potential, (ii) the absence of phase change and (iii) an absence of diffusion limitation over a wide range of weep rates [148-150]. Thanks to the redox reaction contribution, $\mathrm{RuO}_{2}$ electrodes can achieve extremely high capacitance over $700 \mathrm{~F} \mathrm{~g}^{-1}$ in $\mathrm{H}_{2} \mathrm{SO}_{4}$ electrolyte [151], that is about 6 times increase versus porous carbon materials.

However, $\mathrm{RuO}_{2}$ is still limited in practical application due to the cost, lack of abundance, and toxicity [152]. Instead, with merits of low cost and environmentally friendly character, manganese dioxide $\left(\mathrm{MnO}_{2}\right)$ has attracted attention as another pseudocapacitive material. The charge-transfer reactions in $\mathrm{MnO}_{2}$ are achieved from cation insertion in highly accessible sites located at the near-surface of the $\mathrm{MnO}_{2}$ particles [84,153-156] or thin films [157]. As a result, the electrochemical signature of a $\mathrm{MnO}_{2}$ electrode (Figure 6b) also indicates a pseudocapacitive charge storage mechanism. In contrast to $\mathrm{RuO}_{2}$, however, low intrinsic electron conductivity of $\mathrm{MnO}_{2}$ and many other metal oxides $\left(\mathrm{MO}_{x}\right)$ may hinder their practical applications [158].

$\mathrm{Mn}_{3} \mathrm{O}_{4}, \mathrm{Fe}_{3} \mathrm{O}_{4}$, and $\mathrm{MnFe}_{2} \mathrm{O}_{4}$ are materials with the spinel structure that show pseudocapacitive behavior in aqueous 

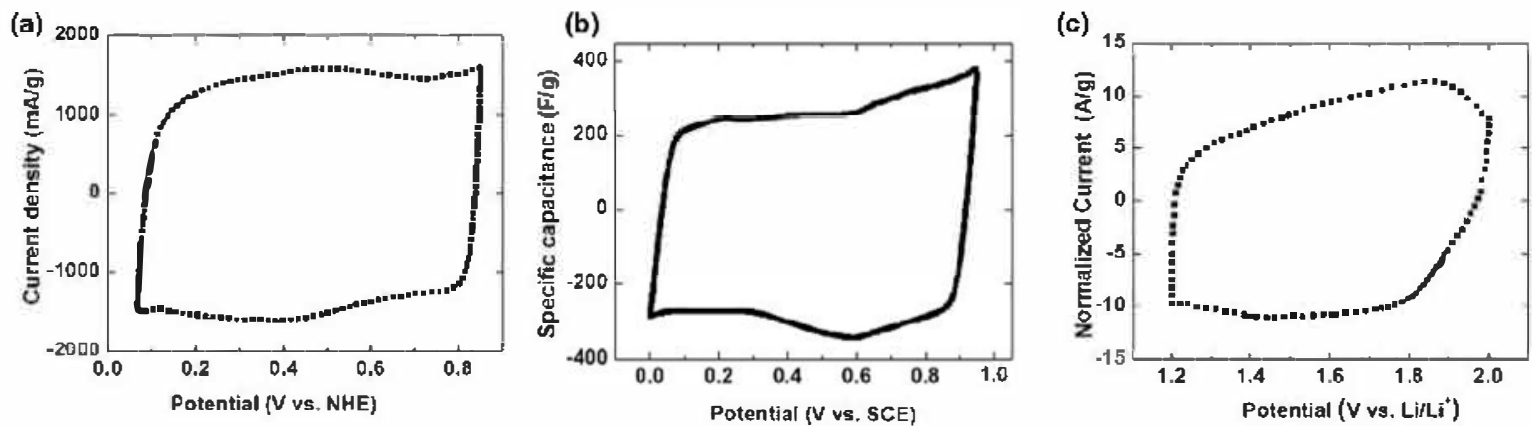

\section{FIGURE 6}

$\mathrm{CV}$ profile of (a) $\mathrm{RuO}_{2} \cdot 0.58 \mathrm{H}_{2} \mathrm{O}$ electrode in $0.5 \mathrm{M} \mathrm{H}_{2} \mathrm{SO}_{4}$ at $2 \mathrm{mV} \mathrm{s}^{-1}$. Adapted with permission from [147]. Copyright (2017) American Chemical Society; (b) $\mathrm{MnO}_{2}$ electrode in $2 \mathrm{M} \mathrm{Na}_{2} \mathrm{SO}_{4}$ at $10 \mathrm{mV} \mathrm{s}^{-1}$. Adapted with permission from [168]; (c) $\mathrm{Nb}_{2} \mathrm{O}_{5}$ phase in $1 \mathrm{M} \mathrm{LiClO}_{4} / \mathrm{PC}$ at $10 \mathrm{mV} \mathrm{s}^{-1}$. Reproduced with permission from Ref. [163].

electrolytes [149]. Like $\mathrm{MnO}_{2}, \mathrm{Mn}_{3} \mathrm{O}_{4}$ [159] suffers from low electrical conductivity and mainly thin coatings can be prepared. Capacitance of $\mathrm{Fe}_{3} \mathrm{O}_{4}$ and $\mathrm{MnFe}_{2} \mathrm{O}_{4}$ remains modest.

In addition to the use of pseudocapacitive materials in aqueous solutions, researchers expanded the concept of pseudocapacitance to materials operating in non-aqueous electrolytes in order to improve energy density further. For example, nanocrystals of $\mathrm{Nb}_{2} \mathrm{O}_{5}$ with tetragonal structure demonstrated intercalation of $\mathrm{Li}^{+}$ions at a very high rate (full charge in $3.6 \mathrm{~s}$ ) at a mean potential of $1.5 \mathrm{~V}$ versus $\mathrm{Li}^{+} / \mathrm{Li}$ [160-164]. The existence of $2 \mathrm{D}$ transport pathways in the structure and minimal volume and structural changes in $\mathrm{Nb}_{2} \mathrm{O}_{5}$ upon $\mathrm{Li}^{+}$intercalation led to fast $\mathrm{Li}^{+}$ion mobility and allowed $125 \mathrm{mAh} \mathrm{g}^{-1}$ (70\% of theoretical capacity) be accessed within 1-min discharge [160]. This reaction, often termed "intercalation pseudocapacitance", offers a generic promise of exploiting intercalation pseudocapacitance to obtain high-rate charge storage devices with tailoreddesigned nanostructured materials [160,162-167]. Depending on the crystalline structure, $\mathrm{Nb}_{2} \mathrm{O}_{5}$ demonstrated capacity of up to $720 \mathrm{Cg}^{-1}$ [164]. Nano-crystalline $\mathrm{MoO}_{2}$ also shows pseudocapacitive responses which stores nearly $200 \mathrm{mAh} \mathrm{g}^{-1}$ in $2 \mathrm{~min}$ [165]. The concept was recently extended to prepare reduced $\mathrm{MoO}_{3 x}$ pseudocapacitive material [166] by introducing oxygen vacancies into orthorhombic $\mathrm{MoO}_{3}$. Such a reduced $\mathrm{MoO}_{3-x}$ rapidly delivers higher capacity than fully oxidized $\mathrm{MoO}_{3}$. Many other nanostructured $\mathrm{MO}_{x}$ may be hypothesized to exhibit a similarly high-rate performance in organic electrolytes. Studies on $\mathrm{Na}^{+}, \mathrm{K}^{+}$and $\mathrm{Li}^{+}$ion batteries may guide the selection of suitable pseudocapacitive materials.

Despite the rich chemistry of metal oxides as pseudocapacitive materials, multiple barriers toward practical applications still exist, such as commonly observed reduced rate performance of thicker $(100+\mu \mathrm{m})$ electrodes with low fraction of conductive additives, lower cycle stability and faster self-discharge rates when compared to EDLCs, particularly at elevated temperatures, in some cases high synthesis or material cost and increased toxicity, in some cases moderate capacitance in organic electrolytes, among others. Yet, the overall strategy to introduce intercalation pseudocapacitive materials in non-aqueous electrolytes appears promising to develop cost-effective and high performance pseudocapacitors.

\section{D MXene materials}

MXenes are two-dimensional (2D) early transition metal carbides and/or nitrides which are produced by selective etching of the A group element from MAX phases, where $\mathrm{M}$ represents transition metals (such as $\mathrm{Sc}, \mathrm{Ti}, \mathrm{Zr}, \mathrm{Hf}, \mathrm{V}, \mathrm{Nb}, \mathrm{Ta}, \mathrm{Cr}, \mathrm{Mo}$, etc.), A is A group element (such as $\mathrm{Al}, \mathrm{Si}, \mathrm{S}, \mathrm{Ga}, \mathrm{Ge}, \mathrm{As}, \mathrm{Cd}, \mathrm{In}, \mathrm{Sn}$, etc) and $\mathrm{X}$ is carbon and/or nitrogen (Figure 8a) [169-171]. Thanks to their unique properties such as 2D structure and high electrical conductivity $\left(>5000 \mathrm{~S} \mathrm{~m}^{-1}\right)$, MXenes have shown great potential as electrode materials for supercapacitor applications [172-175]. One of the most studied MXene is the $\mathrm{Ti}_{3} \mathrm{C}_{2} \mathrm{~T}_{x}$ carbide obtained from the selective $\mathrm{Al}$ etching of $\mathrm{Ti}_{3} \mathrm{AlC}_{2} \mathrm{MAX}$ phase. After washing in water and drying, $\mathrm{Ti}_{3} \mathrm{C}_{2} \mathrm{~T}_{x}$ powder is obtained, where " $\mathrm{T}_{x}$ " represents the surface functional groups (such as $-\mathrm{OH}$ and $-\mathrm{F}$ terminations) present on the surface coming from the etching process.

MXenes have been intensively studied in aqueous electrolytes. The pseudocapacitive charge storage mechanism in $\mathrm{Ti}_{3} \mathrm{C}_{2} \mathrm{~T}_{x}$ MXene results from a change in the oxidation state of $\mathrm{Ti}$, such as evidenced by using XANES technique [176]. A MXene $\mathrm{Ti}_{3} \mathrm{C}_{2} \mathrm{~T}_{x}$ clay-like electrode achieved a volumetric capacitance exceeding $900 \mathrm{~F} \mathrm{~cm}^{-3}$ in $\mathrm{H}_{2} \mathrm{SO}_{4}$ electrolyte [174], suggesting that the proton intercalation between the $\mathrm{Ti}_{3} \mathrm{C}_{2} \mathrm{~T}_{x}$ MXene is mainly responsible for the redox activity of Ti. Freestanding $\mathrm{Ti}_{3} \mathrm{C}_{2} \mathrm{~T}_{x}$ paper electrode has shown smaller yet still impressive volumetric capacitance $\left(300-400 \mathrm{~F} \mathrm{~cm}^{-3}\right)$ in neutral and basic electrolytes where the proton concentration is lower [172].

Recently, new strategies were developed to push further the performance of MXenes to reach ultra-high charge/discharge rates in $\mathrm{H}_{2} \mathrm{SO}_{4}$ electrolyte, exceeding those of conventional EDLCs, with higher volumetric and areal capacitance than ACs (see Figure 7) [177]. For instance, a volumetric capacitance of $1500 \mathrm{~F} \mathrm{~cm}^{-3}$ together with an areal capacitance of $4 \mathrm{~F} \mathrm{~cm}^{-2}$ could be delivered by a $\mathrm{Ti}_{3} \mathrm{C}_{2} \mathrm{~T}_{x}$ MXene hydrogel film electrode prepared by pre-intercalating $\mathrm{H}_{2} \mathrm{SO}_{4}$ molecules between the $2 \mathrm{D}$ MXene layers.

Although the capacitance of MXene electrodes outperforms the best values reported so far for all carbons and most pseudocapacitive materials, the narrow voltage window offered by aqueous electrolytes still hampers the massive development of MXene-based supercapacitors. MXenes were thus further studied 
(a)

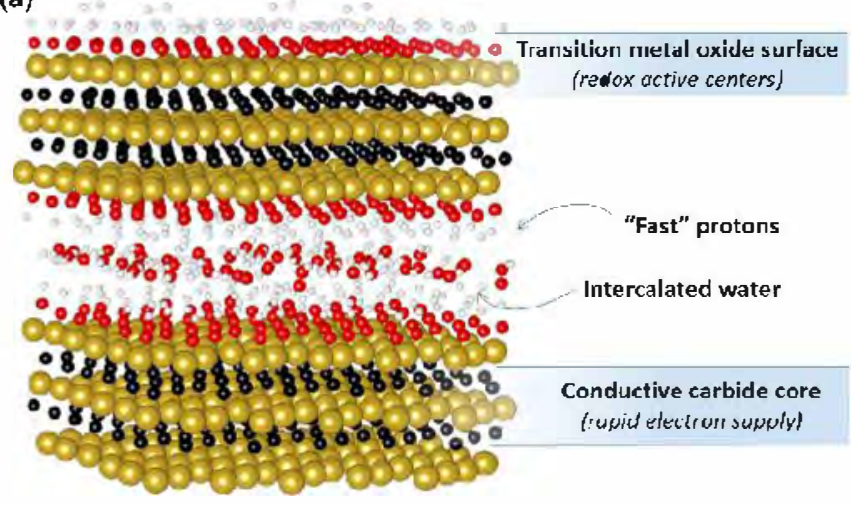

(b)

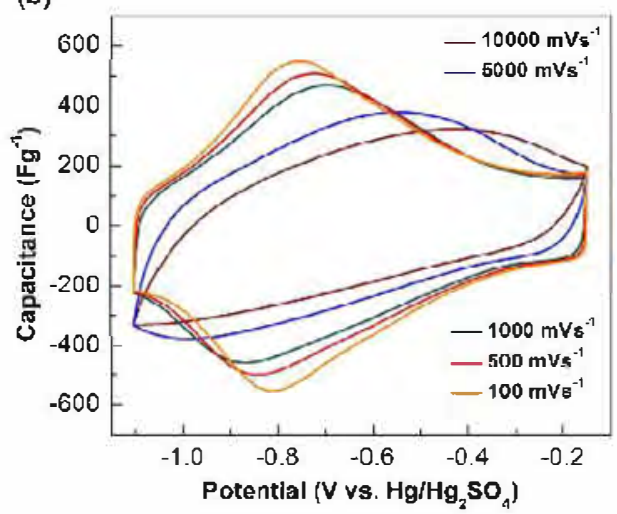

\section{FIGURE 7}

(a) Schematic illustration of MXene structure: MXenes possess excellent conductivity owing to a conductive carbide inner layer along with transition metal oxide-like surfaces. Intercalated water molecules enable high accessibility of the redox-active sites on MXene surfaces to ions, i.e., protons; (b) cyclic voltammetry profiles of macro-porous $\mathrm{Ti}_{3} \mathrm{C}_{2} \mathrm{~T}_{x}$ film with $0.43 \mathrm{mg} \mathrm{cm}^{-2}$ loading and $13-\mu \mathrm{m}$ thickness collected in $3 \mathrm{M} \mathrm{H}_{2} \mathrm{SO}_{4}$ at scan rates from 100 to 10,000 $\mathrm{mV} \mathrm{s}^{-1}$. Adapted with permission from Ref. [177].

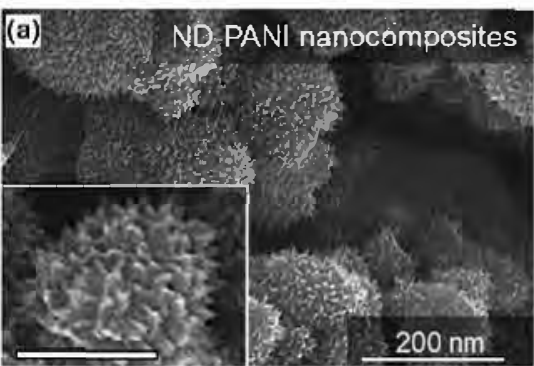

(b)

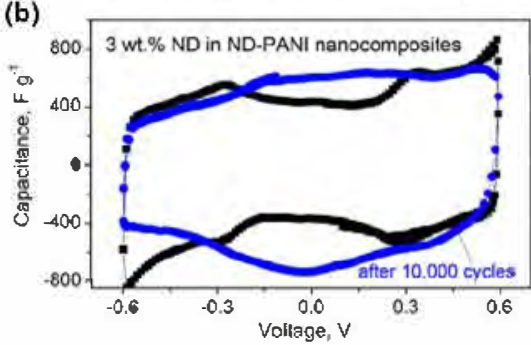

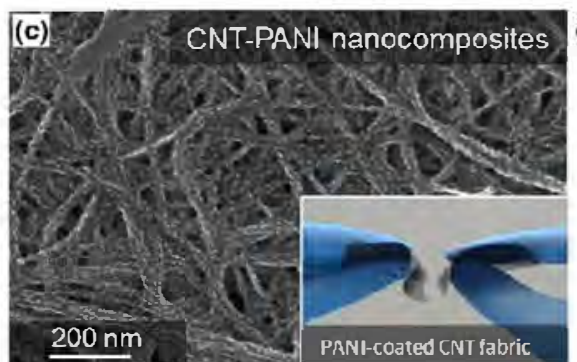

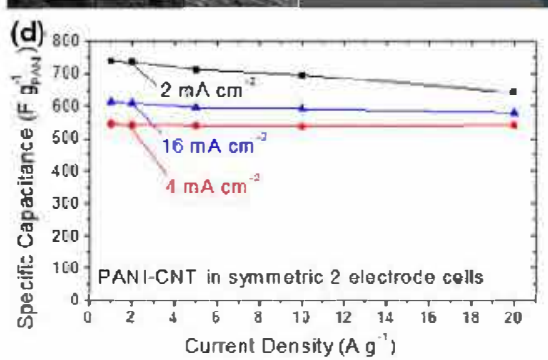

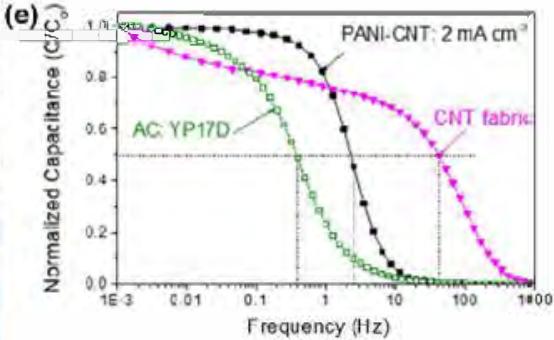

(f)

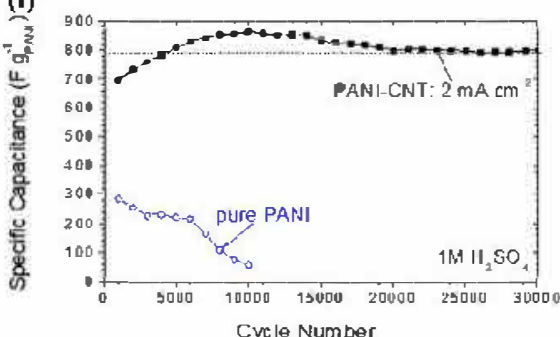

FIGURE 8

Selected examples of the conductive polymer-carbon composites and their electrochemical behavior, such as (a) SEM micrographs of PANI with 3 wt.\% of nanodiamond (ND) soot incorporated into the PANI particles during synthesis; and (b) CV of a symmetric pseudocapacitor with ND-PANI electrodes; (c) SEM of PANI electrodeposited on CNT fabric at the smallest current density of $2 \mathrm{~mA} \mathrm{~cm}^{-2}$; (d) its capacitance retention at high current densities; (e) frequency response in comparison with commonly used AC (YP-17D) and CNT fabric with no PANl; and (f) cycle stability showing over 30,000 stable cycles in $\mathrm{H}_{2} \mathrm{SO}_{4}$ aqueous electrolyte. Adapted with permission from Refs. [184,190].

in non-aqueous electrolytes; however, significantly more modest characteristics have been demonstrated so far. For example, $\mathrm{Ti}_{3} \mathrm{C}_{2} \mathrm{~T}_{x}$-CNT MXene composite electrode showed a capacitance of $85 \mathrm{~F} \mathrm{~g}^{-1}\left(2 \mathrm{mV} \mathrm{s}^{-1}\right)$ within a potential window of $1.8 \mathrm{~V}$ in 1 M EMI-TFSI/acetonitrile organic electrolyte [178]. Furthermore, capacitance of $70 \mathrm{~F} \mathrm{~g}^{-1}\left(20 \mathrm{mV} \mathrm{s}^{-1}\right)$ within a larger voltage window of $3 \mathrm{~V}$ was obtained in solvent-free, neat EMI-TFSI ionic liquid (IL) electrolyte [179]. In-situ XRD measurement as well as in-situ dilatometry experiments revealed the intercalation/ de-intercalation behavior of IL cations and anions [180]. Despite the large voltage window achieved in IL electrolytes, the modest capacitance achieved so far in these electrolytes does not nowadays match the expectations. The capacitance improvement of
MXene electrodes in non-aqueous electrolytes is the next challenge; this will pass through a better understanding of the metal redox activity in these electrolytes.

\section{Conductive polymers}

The pseudocapacitance in Electronically Conducting Polymers (ECPs) is based on the reversible redox reactions of their electrochemical doping/de-doping $[181,182]$. The most common conductive polymers used as pseudocapacitive materials include polyaniline (PANI), polypyrrole (PPy), polythiophene (PT) or its derivatives, and poly(3,4-ethylenedioxythiophene) (PEDOT). These have been tested in both aqueous and organic electrolytes and showed specific capacitance in the range from $\approx 100 \mathrm{~F} \mathrm{~g}^{-1}$ to 
over $600 \mathrm{~F} \mathrm{~g}^{-1}$, depending on the electrolyte composition (typically less than $200 \mathrm{~F} \mathrm{~g}^{-1}$ in organic electrolytes), polymer morphology, doping level and type, the presence and distribution of conductive additives and electrode potential range [183-190].

A significant disadvantage of most conducting polymer electrodes is relatively low cycle stability because of doping on trapping and significant volume changes during charge/discharge cycles, leading to mechanical disintegration [191-193]. The common approaches to overcome this limitation involve formation of polymer-ceramic [194-197] polymer-metal [193,198] and polymer-carbon $[184,199-208]$ composite materials, where thin films of ECPs coated onto carbon or ceramic are used. This approach allows for mitigating the polymer volume changes, introduces additional pores and stabilizes the electrode against mechanical failures. Figure 8 shows examples of PANI-based composites with a specific capacitance of over $600 \mathrm{~F} \mathrm{~g}^{-1}$ achieved in symmetric two electrode configuration with no reduction in the capacitance after 10,000-30,000 cycles (Figure 8b and f) and excellent rate capability (Figure $8 d$ and e) $[184,190]$. Developing conductive polymers that exhibit high specific and volumetric capacitance in organic electrolytes remains a challenging task.

\section{High-rate materials for hybrid devices}

Hybrid supercapacitors, which combine an activated carbon electrode together with a large capacity faradic (pseudocapacitive or battery) electrode, offer a promising strategy for further improving the performance of carbon-based supercapacitors. The concept has been firstly developed in aqueous electrolytes, with the $\mathrm{C} / \mathrm{Ni}(\mathrm{OOH})$ [209-211], $\mathrm{C} / \mathrm{MnO}_{2}[212,213]$ or $\mathrm{C} / \mathrm{PbO}_{2}$ [214] hybrid devices that showed improved energy density versus C/C EDLC systems operating in aqueous electrolytes $[74,210,214,215]$. However, the narrow voltage window available in aqueous electrolytes limits their energy density.

An important step has been made by moving from aqueous to non-aqueous electrolytes, with a drastic gain in energy density thanks to the improved voltage window (Figure 9). One of the first hybrid devices was proposed in 2001 , where $\mathrm{LTO}\left(\mathrm{Li}_{4} \mathrm{Ti}_{5} \mathrm{O}_{12}\right)$ was combined with a positive AC electrode in acetonitrile electrolyte [216] to achieve $3 \mathrm{~V}$ maximum voltage, $20 \mathrm{Wh} \mathrm{kg}^{-1}$ energy density and stability for 4000 cycles. LTO exhibits high theoretical capacity of $175 \mathrm{mAh} \mathrm{g}^{-1}$, safe charging and discharging at a constant potential of $1.55 \mathrm{~V}$ vs. $\mathrm{Li}^{+} / \mathrm{Li}$ (above SEI formation region and well above $\mathrm{Li}$ to avoid plating), very small volumetric changes $(0.2 \%)$ and somewhat low cost [217]. However, the limited power performance achieved in the original device together with the fact that supercapacitor market was not well established at that time hampered the commercial development of these cells. The previously discussed formation of nanocomposites with conductive carbons overcomes the limitations of pure pseudocapacitive or battery electrode materials. For example, the follow-up developments of nanostructured C-LTO composites (such as those described in Figure $10 \mathrm{~h}$ and

(a)

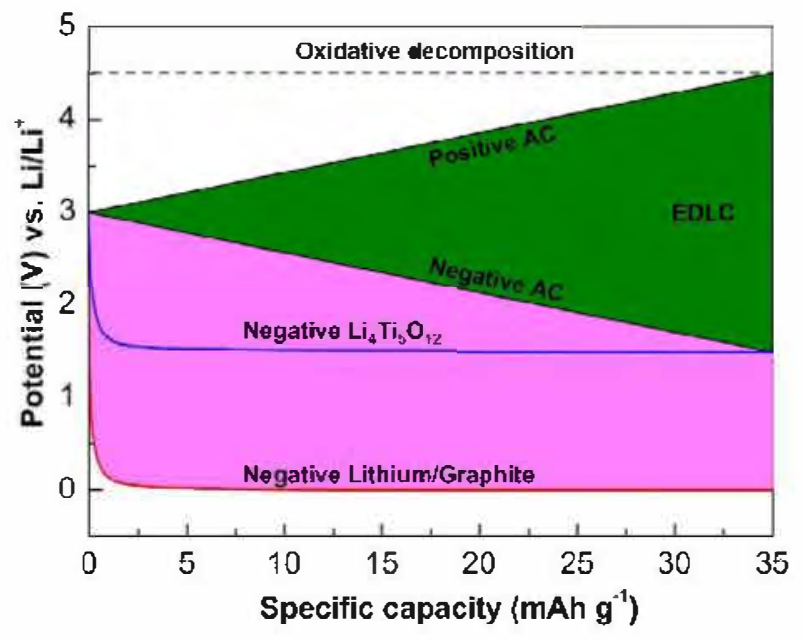

(b)

(ACIAC)

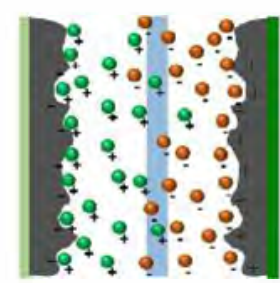

(c)

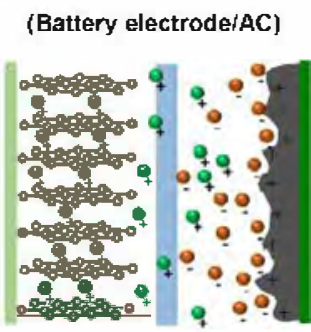

(d) (Pseudocapacitive or fast battery electrode (AC)

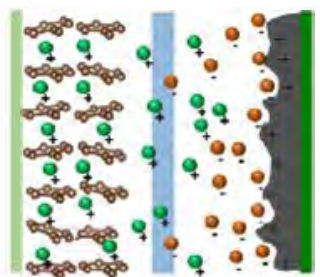

\section{FIGURE 9}

(a) Typical voltage profiles for an EDLC cell and an LIC cell; schematics of (b) EDLC with activated carbon electrode as both positive and negative electrodes; (c) conventional hybrid capacitor with a battery negative electrode and activated carbon (AC) positive electrode and (d) nanohybrid capacitor with a pseudocapacitive or an ultrafast nano-structured battery negative electrode combined with an activated carbon (AC) positive electrode. Adapted from Ref. [219]. 


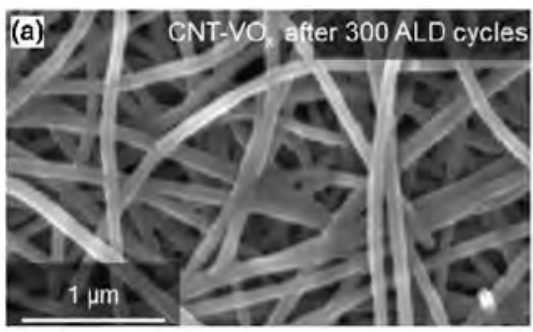

(b)

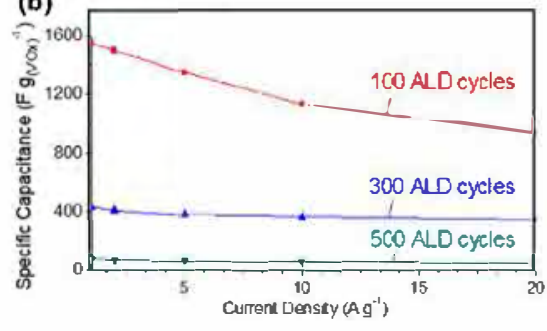

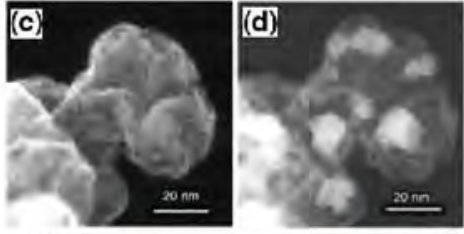

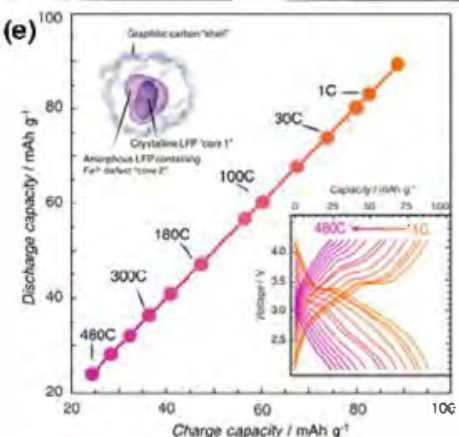

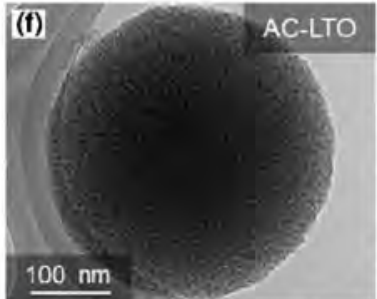

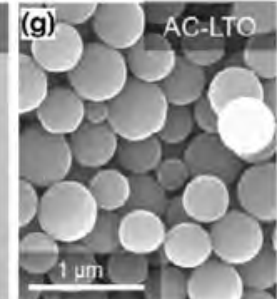

(h)

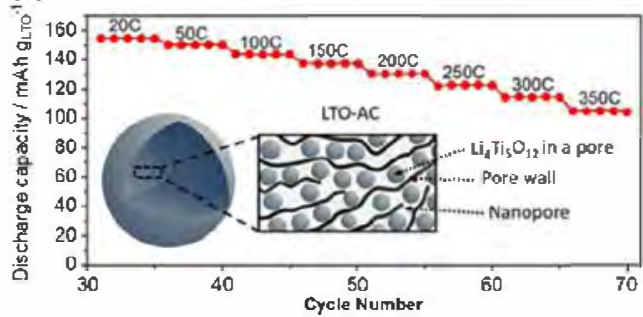

\section{FIGURE 10}

Selected examples of transition metal oxide composites and their electrochemical performances, such as (a) SEM micrographs showing conformal ALD coating of $\mathrm{VO}_{x}$ on the surface of CNTs; and (b) rate response of this composite in a symmetric device using aqueous $8 \mathrm{M} \mathrm{LiCl} \mathrm{electrolyte} \mathrm{as} \mathrm{a} \mathrm{function} \mathrm{of} \mathrm{ALD}$ layer thickness (number of ALD cycles), all reproduced from [229] with permission; (c) SEM micrographs and (d) dark-field images of the UC-derived LFPgraphitic carbon composites, whereby LFP particles are encapsulated within a hollow carbon shell and (e) rate response of this composite in a Li half-cell with an organic electrolyte based on $\mathrm{LiPF}_{6}$-solution in carbonates, an inset shows typical charge-discharge profiles at different $\mathrm{C}$ rates, all reproduced from [246] with permission; (f) TEM and (g) SEM micrographs showing LTO-AC composite particles, where LTO nanoparticles are synthesized within nanopores ( $<3 \mathrm{~nm}$ ) of activated carbon spheres and $(\mathrm{h})$ rate response of this composite in a full cell with LTO-AC anode and AC cathode with an organic electrolyte based on $\mathrm{LiPF}_{6}$-solution in carbonates, all reproduced from [218] with permission.

others) enhanced rate performance of LTO anodes dramatically [218-220].

Today, the combination of a lithium-intercalation graphite anode with a capacitive porous carbon cathode where anion adsorption/desorption occurs, known as the Li-ion capacitor (LiC) technology, is the most commercially successful hybrid device [221]. It is produced by JMEnergy under the name Ultimo $\mathrm{Cell}^{\mathrm{TM}}$. While the cell voltage of a symmetric C/C EDLC can reach $3 \mathrm{~V}$, the combination of a positive EDLC electrode with a negative graphite electrode of a Li-ion battery with $\mathrm{Li}^{+}$intercalation potential below $0.2 \mathrm{~V}$ vs. $\mathrm{Li} / \mathrm{Li}^{+}$allows increasing the cell voltage up to $4.3 \mathrm{~V}$ (Figure $9 \mathrm{a}$ ). At the same time, the capacity of the negative electrode being much higher than that of the positive one, the cell capacity is enhanced [222-225]. However, this increase in voltage is balanced by various flaws inherent to the use of graphite, such as a low intercalation voltage that can lead to safety problems associated with lithium plating at fast charge rates, moderate cycling stability and poor power response. Also, due to the absence of a Li-ion intercalation positive electrode to balance the irreversible $\mathrm{Li}^{+}$ion consumption upon SEI formation at the negative electrode during the first cycle, LiC cells use a prelithiated graphite negative electrode [222,226,227], which increase device assembling complexity and cost.

Intensive research efforts have been developed to propose alternatives to the graphite negative electrode in non-aqueous electrolytes by designing pseudocapacitive or high rate battery materials to be combined with porous carbon electrodes (Figure 9c and d).

For example, $\mathrm{Nb}_{2} \mathrm{O}_{5} / \mathrm{C}$ hybrid cells have shown improved energy and power densities versus EDLC systems [163]. This approach has been recently successfully extended to other materials such as oxygen-defective $\mathrm{MoO}_{3-x}$ that can be used as positive electrodes [166]. Despite the impressive electrochemical performance, the use of somewhat expensive $\mathrm{Nb}$ or Mo transition metals might limit the development of such devices. However, an important step forward has been recently made by Sun et al. [228], who reported the design of a three-dimensional (3D) holey-graphene- $\mathrm{Nb}_{2} \mathrm{O}_{5}$ composite for ultrahigh-rate energy storage at practical levels of mass loading $\mathrm{Nb}_{2} \mathrm{O}_{5}$.

Other material systems are also being explored in order to accelerate the commercialization of hybrid supercapacitors to offer alternatives to high-power batteries. A promising way is the design of high rate battery materials which can be achieved by fine-tuning the material structure and particle size, and preparing composite material to improve the material ionic and electrical percolation networks. Also, in these nanostructured thin films or nanoparticles, the presence of surface defects comes generally with a pseudocapacitive-like electrochemical signature [148-150]. Vanadium oxides $\left(\mathrm{VO}_{x}\right.$, such as $\mathrm{V}_{2} \mathrm{O}_{5}, \mathrm{VO}_{2}$, etc.) are dramatically less expensive than $\mathrm{RuO}_{2}$, but still noticeably costlier than $\mathrm{MnO}_{2}$. Depending on the crystal size and phase, $\mathrm{VO}_{x}$ may exhibit both pseudocapacitive and battery-like behavior with capacitance over $1300 \mathrm{~F} \mathrm{~g}^{-1}$ in aqueous $\mathrm{LiCl}$ electrolyte [229-231]. $\mathrm{VO}_{x}$ suffers from low electrical conductivity and typically requires close proximity of the electrochemically active sites to conductive additives to attain high capacitance values so that mainly thin coatings can be prepared. Other transition metal oxides, such as cobalt oxide $\left(\mathrm{Co}_{3} \mathrm{O}_{4}\right)$ in the form of mesoporous particles [232], nanowires [233], nickel oxide (NiO) in the form of thin films [234-237] and nanosheets [238], mixed Ni-Co oxides [239] and Ni-Co hydroxides [240], mixed Bi-Fe oxide [241], and others also showed medium-to-high capacitance 
values in neutral or basic aqueous electrolytes. Out of these, $\mathrm{Ni}$ comprising materials showed the highest capacitance values, with Ni-Co oxide exhibiting up to $1840 \mathrm{~F} \mathrm{~g}^{-1}$ in $1 \mathrm{M} \mathrm{NaOH}+$ $0.5 \mathrm{M} \mathrm{Na}_{2} \mathrm{SO}_{4}$ electrolyte [239] and $\mathrm{Ni}$-Co layered double

hydroxide exhibiting up to $2100 \mathrm{~F} \mathrm{~g}^{-1}$ in $1 \mathrm{M} \mathrm{KOH}$ solution [240]. Both Co and Ni are sufficiently toxic though. Besides transition metal oxides, oxides of pure metals, such as tin oxide $\left(\mathrm{SnO}_{2}\right)$ [242], indium oxide $\left(\mathrm{In}_{2} \mathrm{O}_{3}\right)$ [243], and bismuth oxide $\left(\mathrm{Bi}_{2} \mathrm{O}_{3}\right)$ [244] also showed capacitance in the range from $100 \mathrm{~F}$ $\mathrm{g}^{-1}$ to $300 \mathrm{~F} \mathrm{~g}_{2}^{-1}$ in aqueous salt-based electrolytes (such as

To overcome relatively low electrical conductivity of most transition metal oxides (which becomes particularly important for thicker, higher loading electrodes commonly used in industry), the use of highly conductive CNTs and graphene additives as well as formation $\mathrm{CNT}^{-\mathrm{MO}_{x}}$ (Figure 10a and b) $[219,220,229]$, graphene- $\mathrm{MO}_{x}$ [245], porous carbon (C)- $\mathrm{MO}_{\boldsymbol{x}}$ (Figure 10c-h) [218,246,247], conductive polymer-MO $\mathrm{MO}_{x}$ [196], nanoporous metal-MO ${ }_{x}[198,230]$ and other (nano)composites have been successfully explored. Still, several factors need to be considered for future industrial impact of such composite technologies. First, it is important to utilize or develop material synthesis routes that offer precisely well-controlled parameters (e.g., size of the $\mathrm{MO}_{x}$, uniformity of $\mathrm{MO}_{x}$ dispersions, weight fraction, pore size distribution, overall porosity, etc.) while being inexpensive and scalable to large industrial volumes. Second, produced (nano)composites should ideally be compatible with current electrode manufacturing equipment employed in cell production and also maintain sufficiently high volumetric capacitance (or capacity) at the electrode level. Finally, all the device-level performance characteristics important for a given application (specific and volumetric energy and power density, self-discharge, cycle stability, calendar life, etc.) should be carefully characterized.

Vapor deposition techniques, such as chemical vapor deposition (CVD) and atomic layer deposition (ALD) have historically been considered too costly for deposition of active materials on conductive substrates and formation of nanocomposites. Yet, the remarkable control they offer in dimensions, chemistry, uniformity, and microstructure of the deposited active materials in combination with the industrial development of large-scale, lower cost deposition systems will likely make them commercially attractive in the future [248]. Most CVD/ALD research focused on the deposition of traditionally and well-studied Liion battery intercalation materials, such as $\mathrm{LiCoO}_{2}$ (LCO) [249], $\mathrm{LiMn}_{2} \mathrm{O}_{4}$ (LMO) [250], $\mathrm{LiFePO}_{4}$ (LFP) [251], vanadium oxide $\left(\mathrm{VO}_{x}\right)$ [229], and titanium oxide $\left(\mathrm{TiO}_{2}\right)$ [252,253]. These vapor deposition techniques have been applied on both flat substrates (thin films) and on the surface of conductive carbons or metal nanowires for high rate performance in batteries or ECs. For example, ALD deposition of thin conformal layer of $\mathrm{VO}_{x}$ onto CNT fabric resulted in some of the highest capacitances and fastest rate performance reported for this material (Figure 10a and b). The main concern of those vapor deposition techniques lies in the small amount (thin-films) of active materials deposited, often resulting in a low areal electrode capacitance $\left(\mathrm{mAh} \mathrm{cm}^{-2}\right)$.

Solution-based approaches may offer a combination of reasonably well controlled and yet noticeably lower cost composite synthesis. In one interesting approach small LTO nanoparticles were synthesized within 0.5-4-nm carbon pores by uniform infiltration of LTO precursor into porous carbon followed by calcination. Carbon pore walls serve as spatial confinements of LTO and provide effective pathways to supply electrons directly to individual LTO nanoparticles. The interconnected open pores remaining in the C-LTO composites allow for the rapid transport of ions, leading to over $100 \mathrm{mAh} \mathrm{g}^{-1}$ specific capacity during \% 6-s discharge [246].

Another interesting approach to bond nano-sized materials directly on a broad range of nanocarbons utilizes "ultra centrifugation" and is called UC treatment [220]. The CNT-LTO $[219,220]$, amorphous C-LFP [246], C-TiO $(B)$ [254] or C- $\mathrm{Li}_{3} \mathrm{VO}_{4}$ [255] nanocomposites prepared using a UC treatment process showed very promising performance characteristics. For example, CNT- $\mathrm{Li}_{4} \mathrm{Ti}_{5} \mathrm{O}_{12}$ (LTO) composite electrodes showed LTO capacity of $130 \mathrm{mAh} \mathrm{g}^{-1}$ at $10 \mathrm{C}$ rate $(10 \mathrm{C}=6-\mathrm{min}$ discharge) and $\approx 80 \mathrm{mAh} \mathrm{g}^{-1}$ at $1200 \mathrm{C}$ rate. Such a remarkably high rate capability of the nanocomposite is achieved through a good dispersion of LTO nanoparticles within a porous matrix of conductive carbon.

In another example, LFP-C (Figure 10c and d) showed LFP capacity of over $80 \mathrm{mAh} \mathrm{g}^{-1}$ at $1 \mathrm{C}$ rate and over $35 \mathrm{mAh} \mathrm{g}^{-1}$ at 300C rate (Figure 10e) [246].

UC treatment has also been used to prepare high-rate positive electrodes. A striking example is the preparation of nanosized $\mathrm{LiFePO}_{4}$ (LFP) crystals encapsulated within hollow-structured graphitic carbons [246]. The composite material has an LFP core [crystalline (core 1) - amorphous (core 2)] - graphitic carbon shell structure as shown in Figure $10 \mathrm{c}-\mathrm{e}$. The amorphous part of the LFP core contains about $50 \%$ of $\mathrm{Fe}^{3+}$ defects. Unlike conventional LFP where $\mathrm{Li}^{+}$intercalation is achieved at constant potential through a two-phase reaction mechanism, galvanostatic charge/discharge profiles of the UC-LFP showed different electrochemical signatures both with plateau and sloping region (Figure 10e).

The sloping profiles below $3.4 \mathrm{~V}$ corresponds to amorphous LFP containing $\mathrm{Fe}^{3+}$ defects, and the $\mathrm{Li}^{+}$diffusion coefficient of the amorphous LFP $\left(10-11 \mathrm{~cm}^{2} \mathrm{~s}^{-1}\right)$ has been found to be two orders of magnitude higher than that of crystalline LFP core phase $\left(10-13 \mathrm{~cm}^{2} \mathrm{~s}^{-1}\right)$ in the plateau region. The LFP-graphitic carbon composites have an extremely high rate capability both in charge and discharge, still delivering about $30 \mathrm{mAh} \mathrm{g}^{-1}$ at $400 \mathrm{C}$ rate (9 s charge or discharge). Such a linear relationship means that the composites can offer a high-power capability of the material in discharge as well as in charge, such as expected for the practical use of hybrid supercapacitors.

Energy storage devices based on hybrid supercapacitors are just being recently commercialized, and this underscores the importance of these new materials. Although the stability of the nanostructured electrode/electrolyte interfaces is still an important issue to be solved, this technology has the potential to offer alternatives to high-power batteries.

\section{Perspectives}

\section{Carbon-based supercapacitors}

Thanks to the combination of in-situ techniques and modeling, important progresses have been made in the understanding of 
ion transport and adsorption in carbon nanopores during the past years. Within the past ten years, we moved from a basic representation of the double layer charge using the Helmholtz model to concepts where ions are partially desolvated and can form co-ion pairs thanks to the creation of image charges at the carbon surface [129]. However, we still fail to explain the existence of different charge compensation at the negative and positive electrode (ion swapping and counter-ion adsorption for instance), as well as the fast ion transport in the nanopores. Research efforts in the future will have to address these points which are of great importance for designing the optimum porous structures in carbon electrodes to maximize the capacitance. Also, the contribution of the image charges from the carbon surface indicates that not only the pore size but also the carbon chemistry and microstructure (presence of defects, dopants, charge carrier density, ionophilic/ionophobic character, etc.) play a role in the establishment of the capacitive behavior. The combination of in-situ techniques (X-ray and neutron scattering, NMR, IR, among others) together with modeling approaches integrating those aspects from the carbon side will help in better depicting the electrochemical processes occurring at porous carbon electrodes.

Advanced electrochemical techniques will also have an important role to play for characterizing the porous carbon/electrolyte interface where the charge separation occurs. Moving from the conventional gravimetric EQCM to EQCM-D (with dissipation) has improved the sensitivity of the technique since local structural changes in the electrode could be tracked [139]. The use of AC-EQCM will allow one to identify the response from individual ions and solvent molecules.

AC-electrogravimetry or AC-EQCM [256] is another EQCM technique where a sinusoidal perturbation is over-imposed to the bias signal such as achieved in impedance spectroscopy. Differently from gravimetric EQCM, AC-EQCM allows the decomposition of a global gravimetric EQCM response into individual cations, anions, and solvent molecules. Perrot's group reported in 2016 the first use of AC-EQCM to study the double layer charging at carbon nanotube electrodes in aqueous electrolyte [257], where they were able to distinguish between low-rate processes (proton adsorption), medium-rate $\left(\mathrm{H}_{2} \mathrm{O}\right.$ exchange) and high-rate (solvated $\mathrm{Na}^{+}$adsorption) at negative potentials. This technique sounds really powerful to investigate the charge storage mechanism in supercapacitor electrodes, since it can, among other, distinguish between the adsorption of different anions or different cations [257].

Finally, strategies to increase the carbon capacitance were proposed by adding a pseudocapacitive contribution to the double layer capacitance or by increasing the electron density of states in porous carbons. Doping carbons with $\mathrm{N}$ or $\mathrm{B}$ elements have led to substantial capacitance increase in aqueous electrolytes, possibly due to pseudocapacitive contributions, although the voltage window remains modest [41]. Also, the decoration of porous carbons with selected redox groups has led to substantial increase in the capacitance [258-260]; however, the presence of redox reactions affects the cyclability. Additionally, the formulation of electrolytes is able to achieve a wider voltage window [261] or to use pores/ions of different sizes at both electrodes to improve the capacitance and power performance [262,263].

\section{Electrolytes}

In the near future new solvents, salts, and ionic liquids should be identified and characterized. The aim of this search should be the creation of a "new wave" of advanced electrolyte components, which are making possible realization of EDLCs with low flammability, wide operation temperature ranges, high energy and high power. In order to generate this new generation of electrolytes, several aspects should be carefully addressed.

First of all, the identification of new components should be carried out using a rational approach. The number of chemicals which could be potentially used as electrolytes in EDLCs is enormous and clearly, this makes the selection of possible alternatives to the state-of-the-art extremely challenging. In this context, the introduction of an effective search process appears of great importance. Recently, it has been shown that the use of computational screening represents a valid strategy to identify new solvents, e.g., CPAME discussed in the previous session [51]. This approach (which is schematically illustrated in Figure 11) represents a novel and powerful tool for the identification of new electrolyte components suitable for EDLCs [51,64]. Nevertheless, further investigations are needed to optimize such a screening and to understand the real advantages associated with this approach [64]. In particular, accounting for interfacial effects and the adsorption properties inside nanopores will be mandatory for predicting the capacitance.

In the past, a systematic investigation of the chemicalphysical properties of new electrolyte components, solvents, and salts, has not been always fully accomplished $[45,46,48]$. In the future, greater attention should be dedicated to the investigation of the transport and thermal properties, as well as to the ion-ion and ion-solvent interactions. This information is essential to understand the influence of an electrolyte on the double layer formation and, thus, for the realization of advanced systems. Recently, interdisciplinary studies, in which theoretical and experimental investigation were combined, have been able to supply novel and important insight about the dynamic of the double layer formation and ion-solvent interactions $[3,128,264]$. This approach appears as a very valuable strategy, and should be strengthened in the future.

Finally, another aspect which should be carefully considered in the future are the interaction occurring between the novel electrolytes and the inactive electrode components $[45,48]$. Until now, this aspect has been only marginally considered. However, it has been shown that processes like anodic dissolution of $\mathrm{Al}$ current collectors and binder dissolution might strongly reduce the performance of EDLCs. For that, also these detrimental processes should be addressed while searching and developing new electrolytes.

\section{Pseudocapacitive materials and hybrid devices}

The outstanding performance of 2D MXene in sulfuric acid electrolyte has revitalized the field of pseudocapacitive materials which were largely limited for years to $\mathrm{MnO}_{2}$ and $\mathrm{RuO}_{2}$. A key challenge is to unlock the redox activity of the transition metal ( $\mathrm{Ti}$ in $\mathrm{Ti}_{3} \mathrm{C}_{2} \mathrm{~T}_{x}$ MXene for instance) in non-aqueous electrolytes to drastically increase the capacitance and reach similar performance than that in aqueous electrolytes $\left(\mathrm{C}>500 \mathrm{~F} \mathrm{~g}^{-1}\right)$. One will also need to investigate the charge storage mechanism as well as 


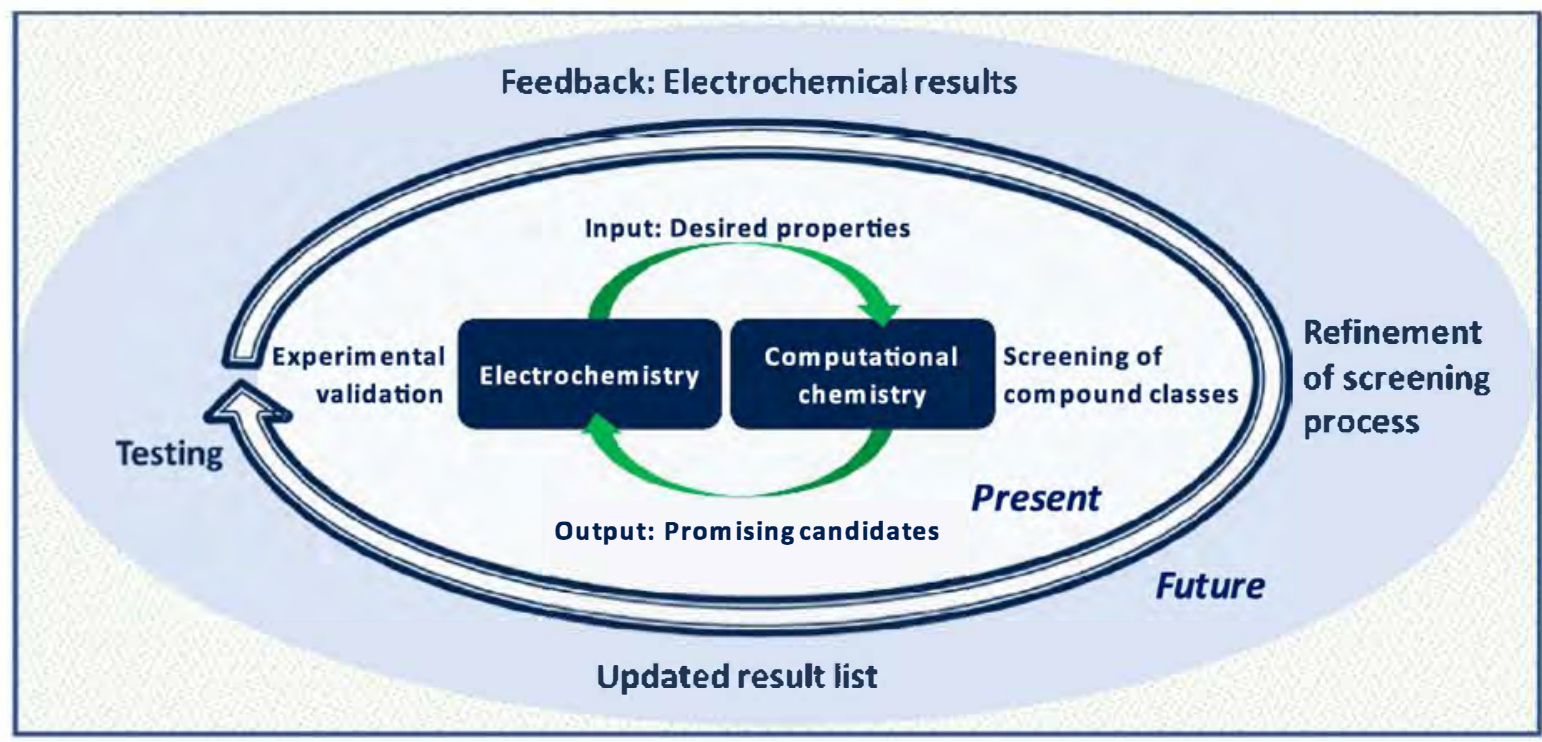

\section{FIGURE 11}

Visual representation of the various steps needed for the identification of novel electrolyte components via computational screening. The inner part describes the action flows needed for the establishment of an effective interface between electrochemistry and computational chemistry. The outer part of the graph describes the steps required for a refinement of the screening process.

the role of the surface groups in the ion intercalation in MXene in non-aqueous electrolytes.

High-rate $\mathrm{Li}^{+}$intercalation achieved in pseudocapacitive nano-crystalline transition metal oxides (such as $\mathrm{Nb}_{2} \mathrm{O}_{5}$ [161] and others) enabled one to extend the concept of pseudocapacitance to non-aqueous electrolytes. The large voltage window offered by non-aqueous electrolytes versus aqueous solution is clearly a key advantage to boost the energy density. Thus, designing metal oxides with controlled structure showing high rate intercalation pseudocapacitive behavior sounds a promising research route to follow as shown in the previous section.

Novel techniques for the low-cost formation of uniform nanocomposites based on pseudocapacitive materials and conductive carbons should be developed to achieve a combination of high capacity, high areal loading and high-rate capability at high-mass loading $\left(>10 \mathrm{mg} \mathrm{cm}^{-2}\right)$. This is a critical step forward toward practical applications such as in hybrid supercapacitors where the combination of high rate and high energy is needed. It will also be critical to conduct systematic studies on the impact of various electrolytes and surface chemistry of these materials on self-discharge, side-reactions, cycle stability and calendar life to identify material systems suitable for a broad range of industrial applications.

Also, thanks to the recent advances made in the development of pseudocapacitive materials operating in non-aqueous electrolytes, it becomes possible to assemble high power, high energy hybrid systems by combining two high-rate redox electrodes in the same device.

Finally, similar to what was achieved for electrical double layer porous carbon electrodes, we may expect major advances in the basic understanding of the pseudocapacitive charge storage mechanism in metal oxide and MXene materials, thanks to the use of computational modeling. This will require efforts to take into account the presence of redox active sites as well as the presence of local charges in the models, but this will certainly be a major research direction in the next coming years.

\section{References}

[1] M. Armand, J.M. Tarascon, Nature 451 (7179) (2008) 652-657.

[2] P. Simon, Y. Gogotsi, Nat. Mater. 7 (11) (2008) 845-854.

[3] M. Salanne et al., Nature Energy 1 (2016) 16070.

[4] A. Pratt et al., Nat. Mater. 13 (2014) 26-30.

[5] W. Gu, G. Yushin, Wiley Interdisciplinary Rev.: Energy Environ. 3 (5) (2014) $424-473$.

[6] P. Simon, Y. Gogotsi, Accounts Chem. Res. 46 (5) (2013) 1094-1103.

[7] X. Zhang et al., RSC Adv. 4 (86) (2014) 45862-45884.

[8] J.K. McDonough et al., Carbon 50 (9) (2012) 3298-3309.

[9] R.Y. Lin et al., J. Phys. Chem. Lett. 2 (19) (2011) 2396-2401.

[10] M. Sevilla, R. Mokaya, Energy Environ. Sci. 7 (4) (2014) 1250-1280.

[11] H. Shi, Electrochim. Acta 41 (10) (1996) 1633-1639.

[12] L. Wei, G. Yushin, Nano Energy 1 (4) (2012) 552-565.

[13] L. Wei et al., Adv. Energy Mater. 1 (2011) 356-361.

[14] E. Redondo et al., Electrochem. Commun. 79 (Supplement C) (2017) 5-8.

[15] J. Chmiola et al., Science 313 (5794) (2006) 1760-1763.

[16] Y. Gogotsi et al., Nat. Mater. 2 (9) (2003) 591-594.

[17] Y.G. Gogotsi, I.-D. Jeon, M.J. McNallan, J. Mater. Chem. 7 (9) (1997) 1841 1848.

[18] A. Jänes et al., Electrochem. Commun. 6 (3) (2004) 313-318.

[19] Z.G. Cambaz et al., J. Am. Ceram. Soc. 89 (2) (2006) 509-514.

[20] A. Jänes, T. Thomberg, E. Lust, Carbon 45 (14) (2007) 2717-2722.

[21] Y. Korenblit et al., ACS Nano 4 (3) (2010) 1337-1344.

[22] Y. Gao et al., J. Power Sources 201 (2012) 368-375.

[23] H. Itoi et al., J. Am. Chem. Soc. 133 (5) (2011) 1165-1167.

[24] H. Nishihara, T. Kyotani, Adv. Mater. 24 (33) (2012) 4473-4498.

[25] A. Kajdos et al., J. Am. Chem. Soc. 132 (10) (2010) 3252-3253.

[26] Y.W. Zhu et al., Science 332 (6037) (2011) 1537-1541.

[27] X.W. Yang et al., Science 341 (6145) (2013) 534-537.

[28] H. Li et al., Energy Environ. Sci. 9 (10) (2016) 3135-3142.

[29] Y. Tao et al., Sci. Rep. 3 (2013) 2975.

[30] Y. Gogotsi, P. Simon, Science 334 (6058) (2011) 917-918.

[31] A. Bianco et al., Carbon 65 (Supplement C) (2013) 1-6.

[32] W.T. Gu et al., Energy Environ. Sci. 6 (8) (2013) 2465-2476.

[33] W.T. Gu, N. Peters, G. Yushin, Carbon 53 (2013) 292-301.

[34] G. Moussa et al., Carbon 105 (Supplement C) (2016) 628-637.

[35] H. Helmholtz, Annalen der Physik und Chemie 243 (7) (1879) 337-382. 
[36] B.E. Conway, Electrochemical Supercapacitors: Scientific Fundamentals and Technological Applications, Kluwer Academic/Plenum, New York, 1999.

[37] M. Thommes et al., Pure Appl. Chem. 87 (9-10) (2015) 1051-1069.

[38] A.V. Neimark et al., Carbon 47 (7) (2009) 1617-1628.

[39] T.A. Centeno, O. Sereda, F. Stoeckli, Phys. Chem. Chem. Phys. 13 (27) (2011) 12403-12406.

[40] N. Jäckel et al., ACS Energy Lett. 1 (6) (2016) 1262-1265.

[41] T. Lin et al., Science 350 (6267) (2015) 1508-1513.

[42] M.Q. Chu, M. Miller, P. Dutta, ACS Cent. Sci. 2 (3) (2016) 175-180.

[43] A. Uysal et al., J. Phys.-Condens. Matter 27 (3) (2015) 032101.

[44] S. Boukhalfa et al., Angew. Chem.-Int. Edit. 52 (17) (2013) 4618-4622.

[45] F. Béguin et al., Adv. Mater. 26 (14) (2014) 2219-2251.

[46] F. Beguin, E. Frackowiak, in: F. Beguin, E. Frackowiak (Eds.), Supercapacitors Materials, Systems, and Applications, Wiley-VCH Verlag GmbH, 2013, https:// doi.org/10.1002/9783527646661. p 568.

[47] C. Zhong et al., Chem. Soc. Rev. 44 (21) (2015) 7484-7539.

[48] A. Balducci, J. Power Sources 326 (2016) 534-540.

[49] M. Ue et al., J. Electrochem. Soc. 144 (8) (1997) 2684-2688.

[50] M. Ue, K. Ida, S. Mori, J. Electrochem. Soc. 141 (11) (1994) 2989-2996.

[51] C. Schütter et al., J. Phys. Chem. C 119 (24) (2015) 13413-13424.

[52] A. Brandt et al., J. Power Sources 204 (2012) 213-219.

[53] F. Ghamouss, A. Brugere, J. Jacquemin, J. Phys. Chem. C 118 (26) (2014) 14107-14123.

[54] A.R. Neale et al., J. Chem. Eng. Data 62 (1) (2016) 376-390.

[55] C. Schütter et al., Electrochim. Acta 220 (2016) 146-155.

[56] O. Hanna, S. Luski, D. Aurbach, J. Electrochem. Soc. 164 (2) (2017) A231-A236.

[57] J. Krummacher, L.H. Hess, A. Balducci, ChemSusChem 10 (21) (2017) 41784189.

[58] J. Kalhoff et al., ChemSusChem 8 (13) (2015) 2154-2175.

[59] A. Laheäär, A. Jänes, E. Lust, J. Electroanal. Chem. 669 (2012) 67-72.

[60] A. Laheäär, A. Jänes, E. Lust, Electrochim. Acta 56 (25) (2011) 9048-9055.

[61] M. Schroeder et al., J. Electrochem. Soc. 160 (10) (2013) A1753-A1758.

[62] K. Chiba et al., J. Electrochem. Soc. 158 (12) (2011) A1320-A1327.

[63] K. Chiba et al., J. Electrochem. Soc. 158 (8) (2011) A872-A882.

[64] C. Schütter et al., J. Power Sources 326 (2016) 541-548.

[65] C. Schütter et al., Electrochim. Acta 224 (2017) 278-284.

[66] Y. Korenblit et al., Adv. Funct. Mater. 22 (8) (2012) 1655-1662.

[67] W.C. West et al., J. Electrochem. Soc. 155 (10) (2008) A716-A720.

[68] E.J. Brandon et al., J. Power Sources 170 (1) (2007) 225-232.

[69] E. Iwama et al., J. Power Sources 219 (Supplement C) (2012) 235-239.

[70] S. Pohlmann, C. Ramirez-Castro, A. Balducci, J. Electrochem. Soc. 162 (5) (2015) A5020-A5030.

[71] S. Pohlmann, A. Balducci, Electrochim. Acta 110 (2013) 221-227.

[72] J. Krummacher et al., ChemElectroChem 4 (2) (2017) 353-361.

[73] A. Brandt, A. Balducci, J. Power Sources 250 (2014) 343-351.

[74] J.P. Zheng, J. Electrochem. Soc. 150 (4) (2003) A484-A492.

[75] J.P. Zheng, J. Huang, T.R. Jow, J. Electrochem. Soc. 144 (6) (1997) 2026-2031.

[76] A. Brandt et al., MRS Bull. 38 (07) (2013) 554-559.

[77] D.R. MacFarlane et al., Energy Environ. Sci. 7 (1) (2014) 232-250.

[78] M. Salanne, Topics Curr. Chem. 375 (3) (2017) 63.

[79] A. Balducci et al., J. Power Sources 165 (2) (2007) 922-927.

[80] M. Lazzari et al., J. Electrochem. Soc. 158 (1) (2011) A22-A25.

[81] C. Largeot et al., Electrochem. Solid St. 14 (12) (2011) A174-A176.

[82] M. Lazzari, F. Soavi, M. Mastragostino, J. Power Sources 178 (1) (2008) 490496.

[83] C. Arbizzani et al., J. Power Sources 185 (2) (2008) 1575-1579.

[84] A. Boisset et al., J. Phys. Chem. C 117 (15) (2013) 7408-7422.

[85] V. Ruiz et al., RSC Adv. 2 (13) (2012) 5591-5598.

[86] A. Krause, A. Balducci, Electrochem. Commun. 13 (8) (2011) 814-817.

[87] R. Palm et al., Electrochem. Commun. 22 (2012) 203-206.

[88] Y. Shim, H.J. Kim, Y. Jung, Faraday Discuss. 154 (2012) 249-263.

[89] N. Handa et al., J. Power Sources 185 (2) (2008) 1585-1588.

[90] M. Yamagata et al., Electrochim. Acta 100 (2013) 275-280.

[91] L. Wei, G. Yushin, J. Power Sources 196 (8) (2011) 4072-4079.

[92] A. Lewandowski et al., J. Power Sources 195 (17) (2010) 5814-5819.

[93] T. Belhocine et al., Green Chem. 13 (11) (2011) 3137-3155.

[94] S. Pohlmann et al., J. Power Sources 273 (2015) 931-936.

[95] S. Pohlmann et al., Electrochim. Acta 153 (2015) 426-432.

[96] E. Coadou et al., J. Phys. Chem. C 117 (20) (2013) 10315-10325.

[97] M. Anouti et al., J. Phys. Chem. C 116 (17) (2012) 9412-9418.

[98] A.R. Neale et al., J. Power Sources 326 (2016) 549-559.

[99] A. Brandt et al., J. Mater. Chem. A 1 (40) (2013) 12669-12678.

[100] R.S. Kühnel, A. Balducci, J. Power Sources 249 (2014) 163-171.
[101] T.J. Simons et al., J. Phys. Chem. B 118 (18) (2014) 4895-4905. [102] P.L. Huang et al., Electrochim. Acta 161 (2015) 371-377.

[103] C. Wolff et al., J. Power Sources 293 (2015) 65-70.

[104] V.L. Martins et al., Phys. Chem. Chem. Phys. 19 (25) (2017) 16867-16874.

[105] X.F. Zhang et al., J. Mater. Chem. A 2 (42) (2014) 17906-17913.

[106] L. Mayrand-Provencher, D. Rochefort, J. Phys. Chem. C 113 (4) (2009) 1632 1639

[107] D. Rochefort, A.L. Pont, Electrochem. Commun. 8 (9) (2006) 1539-1543.

[108] R. Mysyk et al., Electrochem. Commun. 12 (3) (2010) 414-417.

[109] A. Brandt et al., Electrochim. Acta 108 (2013) 226-231.

[110] E. Mourad et al., Nat. Mater. 16 (4) (2017) 446-453.

[111] C. Bodin et al., Faraday Discuss. (2017), https://doi.org/10.1039/C7FD00174F.

[112] H.J. Xie, B. Gelinas, D. Rochefort, Electrochem. Commun. 66 (2016) 42-45.

[113] G.A. Tiruye et al., J. Power Sources 326 (2016) 560-568.

[114] V. Chaudoy et al., J. Power Sources 342 (2017) 872-878.

[115] M. Brachet, T. Brousse, J. Le Bideau, Ecs Electrochem. Lett. 3 (11) (2014) A112A115.

[116] L. Eliad et al., J. Phys. Chem. B 105 (29) (2001) 6880-6887.

[117] L. Eliad et al., Langmuir 21 (7) (2005) 3198-3202.

[118] C. Vix-Guterl et al., Carbon 43 (6) (2005) 1293-1302.

[119] J. Chmiola et al., Angew. Chem. Int. Ed. 47 (18) (2008) 3392-3395.

[120] C. Largeot et al., J. Am. Chem. Soc. 130 (9) (2008) 2730-2731.

[121] L. Xing et al., J. Phys. Chem. Lett. 4 (1) (2013) 132-140.

[122] G. Feng et al., J. Phys. Chem. C 114 (41) (2010) 18012-18016.

[123] C. Zhan et al., Adv. Sci. (Weinh) (2017).

[124] J. Vatamanu, O. Borodin, G.D. Smith, Phys. Chem. Chem. Phys. 12 (1) (2010) $170-182$.

[125] G. Feng, P.T. Cummings, J. Phys. Chem. Lett. 2 (22) (2011) 2859-2864.

[126] D.-E. Jiang, Z. Jin, J. Wu, Nano Lett. 11 (12) (2011) 5373-5377.

[127] S. Kondrat, A. Kornyshev, J. Phys.: Condens. Matter 23 (2) (2011) 022201.

[128] C. Merlet et al., Nat. Mater. 11 (4) (2012) 306-310.

[129] R. Futamura et al., Nat. Mater. 16 (12) (2017) 1225-1232.

[130] C. Merlet et al., Nat. Commun. 4 (2013) 2701.

[131] C. Prehal et al., Nat. Energy 2 (3) (2017) 16215.

[132] M.D. Levi et al., Nat. Mater. 8 (11) (2009) 872-875.

[133] W.Y. Tsai, P.L. Taberna, P. Simon, J. Am. Chem. Soc. 136 (24) (2014) 8722 8728.

[134] J.M. Griffin, A.C. Forse, C.P. Grey, Solid State Nucl. Magn. Reson. 74 (Supplement C) (2016) 16-35.

[135] M. Oschatz, et al., In: Webb, G. A., (ed.), Annual Reports on Nmr Spectroscopy, Vol 87, (2016), pp 237-318

[136] C. Prehal et al., Energy Environ. Sci. 8 (6) (2015) 1725-1735.

[137] S. Boukhalfa et al., ACS Nano 8 (3) (2014) 2495-2503.

[138] M.D. Levi et al., J. Phys. Chem. Lett. 2 (2) (2011) 120-124.

[139] M.D. Levi et al., Electrochim. Acta 232 (2017) 271-284.

[140] M.D. Levi et al., J. Phys. Chem. C 117 (29) (2013) 14876-14889.

[141] M. Deschamps et al., Nat. Mater. 12 (4) (2013) 351-358.

[142] J.M. Griffin et al., Faraday Discuss. 176 (2014) 49-68.

[143] Alexander C. Forse et al., Nat. Energy 2 (3) (2017) 16216.

[144] J.M. Griffin et al., Nat. Mater. 14 (8) (2015) 812-819.

[145] Q. Chen et al., Phys. Chem. Chem. Phys. 16 (36) (2014) 19307-19313.

[146] A.A. Lee et al., Nanotechnology 25 (31) (2014) 315401.

[147] W. Dmowski et al., J. Phys. Chem. B 106 (49) (2002) 12677-12683.

[148] P. Simon, Y. Gogotsi, B. Dunn, Science 343 (6176) (2014) 1210-1211.

[149] V. Augustyn, P. Simon, B. Dunn, Energy Environ. Sci. 7 (5) (2014) 1597-1614.

[150] T. Brousse, D. Bélanger, J.W. Long, J. Electrochem. Soc. 162 (5) (2015) A5185A5189.

[151] J.P. Zheng, P.J. Cygan, T.R. Jow, J. Electrochem. Soc. 142 (8) (1995) 2699-2703.

[152] E. Frackowiak, In Supercapacitors, Wiley-VCH Verlag GmbH \& Co. KGaA (2013) 10.1002/9783527646661.ch6, pp 207-237.

[153] H.Y. Lee, V. Manivannan, J.B. Goodenough, Comptes Rendus de l'Académie des Sciences - Series IIC - Chemistry 2 (11-13) (1999) 565-577.

[154] M. Toupin, T. Brousse, D. Bélanger, Chem. Mat. 16 (16) (2004) 3184-3190.

[155] O. Ghodbane et al., J. Power Sources 206 (Supplement C) (2012) 454-462.

[156] H.-A. Pan et al., J. Electrochem. Soc. 162 (5) (2015) A5106-A5114.

[157] S.C. Pang, M.A. Anderson, T.W. Chapman, J. Electrochem. Soc. 147 (2) (2000) $444-450$.

[158] G.P. Wang, L. Zhang, J.J. Zhang, Chem. Soc. Rev. 41 (2) (2012) 797-828.

[159] D.P. Dubal et al., Appl. Surf. Sci. 256 (14) (2010) 4411-4416.

[160] J.W. Kim, V. Augustyn, B. Dunn, Adv. Energy Mater. 2 (1) (2012) 141-148.

[161] V. Augustyn et al., Nat. Mater. 12 (6) (2013) 518-522.

[162] A.A. Lubimtsev et al., J. Mater. Chem. A 1 (47) (2013) 14951-14956.

[163] J. Come et al., J. Electrochem. Soc. 161 (5) (2014) A718-A725. 
[164] T. Ohzuku, K. Sawai, T. Hirai, J. Power Sources 19 (4) (1987) 287-299.

[165] H.-S. Kim et al., J. Electrochem. Soc. 162 (5) (2015) A5083-A5090.

[166] H.-S. Kim et al., Nat. Mater. 16 (4) (2017) 454-460.

[167] T. Brezesinski et al., Nat. Mater. 9 (2) (2010) 146-151.

[168] C. Ye, Z.M. Lin, S.Z. Hui, J. Electrochem. Soc. 152 (6) (2005) A1272-A1278.

[169] M. Naguib et al., Adv. Mater. 23 (37) (2011) 4248-4253.

[170] M. Alhabeb et al., Chem. Mat. 29 (18) (2017) 7633-7644.

[171] B. Anasori, M.R. Lukatskaya, Y. Gogotsi, Nat. Rev. Mater. 2 (2) (2017) 16098.

[172] M.R. Lukatskaya et al., Science 341 (6153) (2013) 1502-1505.

[173] M. Hu et al., Chem. Commun. 51 (70) (2015) 13531-13533.

[174] M. Ghidiu et al., Nature 516 (7529) (2014) 78-81.

[175] X.F. Wang et al., J. Am. Chem. Soc. 137 (7) (2015) 2715-2721.

[176] M.R. Lukatskaya et al., Adv. Energy Mater. 5 (2015) 15. 1500589.

[177] M.R. Lukatskaya et al., Nat. Energy 2 (2017) 8. 17105.

[178] Y. Dall'Agnese et al., J. Power Sources 306 (2016) 510-515.

[179] Z. Lin et al., J. Power Sources 326 (2016) 575-579.

[180] Z. Lin et al., Electrochem. Commun. 72 (2016) 50-53.

[181] B.E. Conway, J. Electrochem. Soc. 138 (6) (1991) 1539-1548.

[182] Y.M. Vol'fkovich, T.M. Serdyuk, Russ. J. Electrochem. 38 (9) (2002) 935-958.

[183] F. Fusalba et al., J. Electrochem. Soc. 148 (1) (2001) A1-A6.

[184] I. Kovalenko, D.G. Bucknall, G. Yushin, Adv. Funct. Mater. 20 (22) (2010) 3979-3986.

[185] J. Wang et al., J. Power Sources 196 (4) (2011) 2373-2379.

[186] L.Z. Fan, J. Maier, Electrochem. Commun. 8 (6) (2006) 937-940.

[187] M. Mallouki et al., J. Solid State Electrochem. 11 (3) (2007) 398-406.

[188] F. Fusalba et al., Chem. Mat. 12 (9) (2000) 2581-2589.

[189] J. Wang et al., J. Power Sources 163 (2) (2007) 1120-1125.

[190] J. Benson et al., Adv. Mater. 25 (45) (2013) 6625-6632.

[191] G.A. Snook, P. Kao, A.S. Best, J. Power Sources 196 (1) (2011) 1-12.

[192] L.L. Tu, C.Y. Jia, Prog. Chem. 22 (8) (2010) 1610-1618.

[193] D. Aradilla, F. Estrany, C. Aleman, J. Phys. Chem. C 115 (16) (2011) 84308438.

[194] Jaidev et al., J. Mater. Chem. 21 (44) (2011) 17601-17605.

[195] L. Chen et al., J. Power Sources 195 (11) (2010) 3742-3747.

[196] F.-J. Liu, J. Power Sources 182 (1) (2008) 383-388.

[197] X. Zhang et al., J. Power Sources 173 (2) (2007) 1017-1023.

[198] X. Lang et al., Nat. Nanotechnol. 6 (4) (2011) 232-236.

[199] V. Gupta, N. Miura, Electrochim. Acta 52 (4) (2006) 1721-1726.

[200] G.-M. Zhou et al., New Carbon Mater. 26 (3) (2011) 180-186.

[201] L. Zheng et al., J. Solid State Electrochem. 15 (4) (2010) 675-681.

[202] W.-X. Liu et al., New Carbon Mater. 26 (3) (2011) 217-223.

[203] J. Ge, G. Cheng, L. Chen, Nanoscale 3 (8) (2011) 3084-3088.

[204] C. Yuan et al., Chem. Lett. 39 (8) (2010) 850-851.

[205] M. Yang et al., Electrochim. Acta 55 (23) (2010) 7021-7027.

[206] H. Gómez et al., J. Power Sources 196 (8) (2011) 4102-4108.

[207] K. Zhang et al., Chem. Mat. 22 (4) (2010) 1392-1401.

[208] J. Yan et al., Carbon 48 (2) (2010) 487-493.

[209] P. Simon, T. Brousse, F. Favier, Supercapacitors Based on Carbon or Pseudocapacitive Materials, John Wiley, 2017, https://doi.org/10.1002/ 9781119007333. ch4, pp 57-75.

[210] I.N. Varakin, A.B. Stepanov, V.V. Menukhov, Capacitor with a double electrical layer. Google Patents (1997)

[211] A.B. Stepanov, I.N. Varakin, V.V. Menukhov, Double-layer capacitor. Google Patents (1999).

[212] M.S. Hong, S.H. Lee, S.W. Kim, Electrochem. Solid-State Lett. 5 (10) (2002) A227-A230.

[213] V. Khomenko, E. Raymundo-Piñero, F. Béguin, J. Power Sources 153 (1) (2006) 183-190.

[214] W.G. Pell, B.E. Conway, J. Power Sources 136 (2) (2004) 334-345.
[215] S. Razoumov, et al., Asymmetric electrochemical capacitor and method of making. Google Patents (2001)

[216] G.G. Amatucci et al., J. Electrochem. Soc. 148 (8) (2001) A930-A939.

[217] T. Rauhala et al., J. Power Sources 331 (Supplement C) (2016) 156-166.

[218] E. Zhao et al., ACS Nano 10 (4) (2016) 3977-3984.

[219] K. Naoi et al., Energy Environ. Sci. 5 (11) (2012) 9363-9373.

[220] K. Naoi et al., J. Power Sources 195 (18) (2010) 6250-6254.

[221] M. Galiński, A. Lewandowski, I. Stępniak, Electrochim. Acta 51 (26) (2006) 5567-5580.

[222] S.R. Sivakkumar, J.Y. Nerkar, A.G. Pandolfo, Electrochim. Acta 55 (9) (2010) 3330-3335.

[223] A. Krause et al., J. Power Sources 196 (20) (2011) 8836-8842.

[224] S.R. Sivakkumar, A.G. Pandolfo, Electrochim. Acta 65 (Supplement C) (2012) 280-287.

[225] J. Ding et al., Energy Environ. Sci. 8 (3) (2015) 941-955.

[226] C. Decaux et al., Electrochim. Acta 86 (Supplement C) (2012) 282-286.

[227] S.R. Sivakkumar, A.S. Milev, A.G. Pandolfo, Electrochim. Acta 56 (27) (2011) 9700-9706.

[228] H. Sun et al., Science 356 (6338) (2017) 599-604.

[229] S. Boukhalfa, K. Evanoff, G. Yushin, Energy Environ. Sci. 5 (5) (2012) 6872 6879 .

[230] J. Benson et al., ACS Nano 6 (1) (2012) 118-125.

[231] D. Sun et al., Adv. Funct. Mater. 14 (12) (2004) 1197-1204.

[232] D.W. Wang, Q.H. Wang, T.M. Wang, Inorg. Chem. 50 (14) (2011) 6482-6492.

[233] X.-H. Xia et al., J. Mater. Chem. 21 (25) (2011) 9319-9325.

[234] K.W. Nam, W.S. Yoon, K.B. Kim, Electrochim. Acta 47 (19) (2002) 3201-3209.

[235] E.E. Kalu et al., J. Power Sources 92 (1-2) (2001) 163-167.

[236] V. Srinivasan, J.W. Weidner, J. Electrochem. Soc. 147 (3) (2000) 880-885.

[237] K.C. Liu, M.A. Anderson, J. Electrochem. Soc. 143 (1) (1996) 124-130.

[238] K.K. Purushothaman et al., ACS Appl. Mater. Interfaces 5 (21) (2013) $10767-$ 10773.

[239] G. Wang et al., J. Power Sources 217 (2012) 554-561.

[240] V. Gupta, S. Gupta, N. Miura, J. Power Sources 175 (1) (2008) 680-685.

[241] C.D. Lokhande et al., Electrochem. Commun. 9 (7) (2007) 1805-1809.

[242] K.R. Prasad, N. Miura, Electrochem. Commun. 6 (8) (2004) 849-852.

[243] K.R. Prasad, K. Koga, N. Miura, Chem. Mat. 16 (10) (2004) 1845-1847.

[244] F.-L. Zheng et al., Chem. Commun. 46 (27) (2010) 5021-5023.

[245] G. Yu et al., Nano Lett. 11 (10) (2011) 4438-4442.

[246] K. Naoi et al., Energy Environ. Sci. 9 (6) (2016) 2143-2151.

[247] Z. Chen et al., Adv. Funct. Mater. 19 (21) (2009) 3420-3426.

[248] X. Wang, G. Yushin, Energy Environ. Sci. 8 (7) (2015) 1889-1904.

[249] M.E. Donders et al., J. Electrochem. Soc. 160 (5) (2013) A3066-A3071.

[250] K. Tadanaga et al., Mater. Res. Bull. 53 (2014) 196-198.

[251] C.Y. Wu et al., J. Phys. Chem. C 115 (46) (2011) 23090-23095.

[252] M.L. Lee et al., J. Power Sources 244 (2013) 410-416.

[253] X. Sun et al., J. Electrochem. Soc. 159 (4) (2012) A364-A369.

[254] K. Naoi et al., Adv. Mater. 28 (31) (2016) 6751-6757.

[255] E. Iwama et al., ACS Nano 10 (5) (2016) 5398-5404.

[256] C. Gabrielli et al., Electrochim. Acta 44 (24) (1999) 4217-4225.

[257] F. Escobar-Teran et al., Electrochem. Commun. 70 (Supplement C) (2016) 7377.

[258] E. Lebegue et al., J. Mater. Chem. 21 (33) (2011) 12221-12223.

[259] E. Lebegue et al., J. Mater. Chem. A 2 (23) (2014) 8599-8602.

[260] A.A.J. Torriero, Electrochim. Acta 137 (Supplement C) (2014) 235-244.

[261] K.L. Van Aken, M. Beidaghi, Y. Gogotsi, Angew. Chem. Int Ed. 54 (16) (2015) 4806-4809.

[262] X. Wang et al., J. Am. Chem. Soc. 139 (51) (2017) 18681-18687.

[263] J. Segalini et al., Electrochem. Commun. 15 (1) (2012) 63-65.

[264] P. Ray et al., J. Phys. Chem. C 120 (23) (2016) 12325-12336. 